\title{
Solution of Economic Load Dispatch Problems Using Novel Improved Harmony Search Algorithm
}

Boudjella Houari $^{1}$, Laouer Mohammed ${ }^{2}$, Bouzeboudja Hamid ${ }^{1}$, Ayad Ahmed Nour El Islam³, Benhamida Farid ${ }^{4}$, Saad Abdallah ${ }^{5}$

${ }^{1}$ Department of Electrical Engineering, University of Sciences and Technology of OranMohamed-Boudiaf (USTO-MB), Oran, Algeria

${ }^{2}$ Department of Science and Technologie, SALHI Ahmed University Center, Naama, Algeria

${ }^{3}$ Department of Electrical Engineering, KASDI Merbah University, Ouargla, Algeria

${ }^{4}$ Department of Electrical Engineering, Djilali Liabes University, Sidi Bel Abbes, Algeria

${ }^{5}$ Department of Electrical system Engineering, ENSEM, University Hassan II, Casablanca, Morocco ${ }^{1}$ houari.boudjella@univ-usto.dz, ${ }^{2}$ Laouer@yahoo.fr, ${ }^{1}$ hbouzeboudja@yahoo.fr,

3ayadnourislam@yahoo.fr, ${ }^{4}$ farid.benhamida@yahoo.fr, ${ }^{5}$ saad.abdal@gmail.com

Abstract: In this work, an efficient modified harmony search algorithm namely self-adaptive improved harmony search algorithm (SIHS) is proposed to solve economic load dispatch (ELD) problem with considering valve-point loading effects (VPE). The bandwidth parameter within the proposed approach varying dynamically at each new iteration to enhance the accuracy and the convergence velocity of the conventional HSA. To prove the effectiveness and the robustness of the proposed technique, the SIHS is tested on three ELD test systems including VPE: 3-units systems, 13-units system with two different levels of load demand, and 40-units system. Obtained results from SIHS are comparatively measured using 36 comparative algorithms including conventional HS algorithm. The numerical results have proved that the SIHS is more efficient for solving the ED with VPE than many other methods published recently.

Keywords: Non-convex economic dispatch, harmony search optimization, valve-point effects

\section{Introduction}

The ELD problem is among the most crucial decisions, making in power system operation, to return a profit on the capital invested. The aims of ELD is to meet the system load, at the minimum operating cost needed to satisfy the transmission and operational constraints [1]. ELD is applied to optimize each generating level in the system, in order to decrease the total fuel cost of thermal units while still covering power demand and power losses [2].

The fuel cost in classical ED problems is generally presented by a quadratic function without considering the power loss and operating limits constraints. Practically, some operational constraints such as the active power losses, valve-point effects, unit-ramp rate limits (RRL), prohibited operating zones (POZ), multifuel effects, becomes the dispatch problem more complex and non-differentiable [3].

There are many classical optimization approaches available in the literature to solve the based ELD problem together with, Lagrangian relaxation method (LR) [4], Lambda-iterations method [5], quadratic programming (QP) algorithm [6], linear programming (LP) technique [7], dynamic programming (DP) method [8], etc. Not all these traditional methods can be employed to resolve the complicated ELD problems for global optimum scheduling as they regularly entice at a local minimum [9].

To overcome these deficiencies, a lot of researchers focus on many modern metaheuristic techniques due to their efficiency in finding the local minimum at a reasonable simulation time such as, evolutionary programming techniques (EP) [10], ant colony optimization (ACO) [11], or genetic algorithm (GA) [12]. These methods have been employed to solving ED problem in particular with VPE.

Received: November $14^{\text {th }}, 2019$. Accepted: March $25^{\text {th }}, 2021$

DOI: $10.15676 /$ ijeei.2021.13.1.13 
In the last five years, a lot of swarm intelligence algorithms have been applied to deal with the ELD problem such as, $\mathrm{MVMO}^{\mathrm{S}}$ in [13], a DPSO-Sine algorithm is used in [14], chaosenhanced cuckoo search (CS-A)[15], invasive weed optimization (IWO)[16], grey wolf optimization (GWO)[17]. These metaheuristic techniques mentioned above have the potential to improve the computation accuracy and convergence to the optimal solution.

Researchers have established several hybrid optimization techniques to improve the behavior and the effectiveness of the population-based algorithms by combining multiple metaheuristic algorithms or algorithm components to solving ELD problem with VPE. A hybrid (DSPSO-TSA) approach is applied in [12], PSO algorithm hybrid with sequential quadratic programming (PSO-SQP) in [18], fuzzy adaptive PSO integrating variable differential evolution (FAPSO-VDE)[19], a (VCF-PSO) strategy is utilized in [20], and hybrid differential evolution with BBO algorithm (DE-BBO) is used in [21]. Combination between continuous GRASP and self-adaptive DE algorithm (C-GRASP-SaDE) in [22] and hybrid $\beta$-hill climbing optimizer with GWO ( $\beta$-GWO) in [23] are recently applied to deal with largescale ED of power systems.

In the latest years, various modern approaches based on metaheuristic algorithms were broadly implemented for the complex ELD problems with non-convex fuel cost functions due to (VPE) and practical constraints taking into account (RRL), (POZ), multi-fuel options, and power spinning reserve. For example, in the literature [24], a granular computing method (GrC) has been proposed to increase the resolution accuracy, a multi-behavior combination (MBC-DE) is implemented in [25]. An across neighborhood search (ANS) is suggested in [26]. In reference [27], an improved artificial cooperative search algorithm (IACS) is addressed to solving non-convex ED problems with VPL effects. A new variant of JAYA algorithm named (MP-CJAYA) is developed in [28]. Chaotic bat algorithm (CBA) in literature [29], is successfully implemented for solving ED problems with highly levels of complexity. Hybrid CRO technique with DE algorithm (HCRO-DE) proposed in literature [30], is applied to deal with large-scale economic dispatch.

Various metaheuristic approaches have been effectively employed to solve multi-objective ED such as, (IS) algorithm in [31], flower pollination algorithm (FPA) implemented in [32] and (OGS) algorithm suggested in literature [33].

Harmony search (HS) algorithm is one of the most famous metaheuristic approaches, originally invented by Geem et al [34], which draws inspiration from the musical process to attain an agreeable harmony. HS technique, takes some major advantages compared with other metaheuristics, such as EP, GA, DE, PSO and TS, which is simple in concept and structure, converges quickly to the optimum and easy to implement on optimization problems [35]. Thus, there are several monographs [36]-[38] addressed the advances of HS method and its variants.

A plenty of variants HSA, have been studied to improving algorithm-optimizing performance. Research works presented in literature [39]-[48], give some major variants of the basic HS algorithm published in the past decade. An updated review and analysis of the latest developments of the HSA and its application into engineering optimization have been discussed in [49]-[54].

Many variants techniques based HS algorithm to solve ED problems with VPE are available in the literature [55]-[58]. ED problem with considering operational limits constraints such as POZ, power loss and RRL, was solving by some hybrid metaheuristic methods with original HSA such as mentioned in literature [59]-[62].

The objectif of this article is to propose a simplified, robust, and effective modified HSA, which may be more effective than the ELD-based metaheuristic methods described within the recent published literature. In the initialization phase of HSA, all parameters are fixed value and cannot be varied during the generation process. Thus, in the proposed SIHS, the bandwidth is dynamically updating at each iteration. The proper selection of SIHS parameters values for all cases studied is considered as one of the challenging tasks, because parameter-setting strategy is problem dependent and size of test systems, one parameter setting strategy is suitable for one problem but may perform badly for another. To affirm the effectiveness, 
accuracy, and scalability of the suggested method, SIHS it is apply for the first time to solve the ED problem in three test systems having 3,13 and 40 generators considering VPE. The statistical results are as compared with 35 algorithms existing in the recent literature.

The rest of this article is structured as follows: the definition and mathematically formulation of the ELD problem are offered in section 2, while section 3 addresses a brief description of the HSA. Section 4, describes the process of the proposed SIHS for ELD in depth. The obtained results are carefully studied and analyzed in section 5. Finally, conclusion and future suggestions are given in section 6.

\section{Economic Load Dispatch Formulation}

The aim of the usual ED problem is to dispatch the power output of each generator to meet the load demand at a specified time [10]. Generally, the fuel cost function similar to the scheduling results may be expressed as a quadratic function of the outputs from the generators [1], [2], which may be commonly formulated as follows:

$$
\min F_{t}=\sum_{i=1}^{N} F_{i}\left(P_{i}\right)
$$

where $N$ is the number of generating units $\mathrm{s}, F_{t}$ is the total fuel cost $(\$ / \mathrm{h})$ while meeting the load demand, $F_{i}\left(P_{i}\right)$ is the fuel cost $(\$ / \mathrm{h})$ of $i$ th generator with output $P_{i}$.

Approximately, the fuel cost curve of a thermal generating unit may be formulated as a quadratic polynomial by the following equation:

$$
F_{i}\left(P_{i}\right)=a_{i} \cdot P_{i}^{2}+b_{i} \cdot P_{i}+c_{i}
$$

Where, $a_{i}, b_{i}, c_{i}$, are the coefficients of the fuel cost corresponding of generator i. Eq. (2) is subject to the following constraints [1], [2]:

a. Power balance constraint

$$
\sum_{i=1}^{N} P_{i}=P_{D}+P_{L}
$$

where $P_{D}$ and $P_{l}$ is the value of the demanded power and the whole power loss respectively. $P_{\text {Loss }}$ is approximately calculated by Kron's formula [28]:

$$
P_{L}=\sum_{i=1}^{N} \sum_{j=1}^{N} P_{i} B_{i j} P_{j}+\sum_{i=1}^{N} B_{\mathrm{o} i} P_{i}+B_{\mathrm{oo}}
$$

where $P_{i}$ and $P_{j}$ are the active power injections at $i^{\text {th }}$ and $j^{\text {th }}$ buses and $B_{i j}, B_{i 0}, B_{00}$ are the loss coefficients.

In the studies [14], [15], [18], [19], [62], power losses are ignored to gain simplicity. Therefore, transmission losses are neglected in this work $\left(\mathrm{P}_{\text {Loss }}=0\right)$.

b. Generator operating limits

$$
P_{i}^{\min } \leq P_{i} \leq P_{i}^{\max }, \quad i=1,2, \ldots, N
$$

where $P_{i}^{\min }$ and $P_{i}^{\max }$ are the lower and upper boundary power of $i^{\text {th }}$ generator.

In reality, the ripple effects induced by modern steam turbines with multi-valve, create nonlinearity and no convexity in the fuel cost function [24], [32] as proven in Figure.1. So its function can be expressed by a sinusoidal term to the quadratic cost function as follows [20]:

$$
F_{i}^{\prime}\left(P_{i}\right)=a_{i} \cdot P_{i}^{2}+b_{i} \cdot P_{i}+c_{i}+\left|e_{i} \sin \left(f_{i}\left(P_{i}^{\min }-P_{i}\right)\right)\right|
$$

where $e_{i}$, and $f_{i}$ are cost coefficients of $i$ th generator due to VPE. In this case, the objective function of the ELD problem can be expressed as [18], [23]:

$$
\min F_{t}=\sum_{i=1}^{N} F_{i}^{\prime}\left(P_{i}\right)=\sum_{i=1}^{N}\left(a_{i} \cdot P_{i}^{2}+b_{i} \cdot P_{i}+c_{i}+\left|e_{i} \sin \left(f_{i}\left(P_{i}^{\min }-P_{i}\right)\right)\right|\right)
$$


Table 1. Abbreviations of the comparative methods.

\begin{tabular}{|c|c|c|c|}
\hline Key & Year & Description & Ref \\
\hline ACHS & 2014 & $\begin{array}{l}\text { Hybrid Harmony Search with Arithmetic Crossover } \\
\text { Operation }\end{array}$ & {$[61]$} \\
\hline $\mathrm{ACO}$ & 2010 & Ant Colony Optimization & {$[11]$} \\
\hline ANS & 2018 & Across Neighborhood Search & [26] \\
\hline CBA & 2016 & Chaotic Bat Algorithm & [29] \\
\hline $\begin{array}{l}\text { C-GRASP- } \\
\text { SaDE }\end{array}$ & 2017 & $\begin{array}{l}\text { Hybrid Continuous GRASP with Self-Adaptive Differential } \\
\text { Evolution }\end{array}$ & [22] \\
\hline CIHSA & 2019 & Chaotic Improved Harmony Search Algorithm & [62] \\
\hline CS-A & 2016 & Chaos-Enhanced Cuckoo Search (A) & {$[15]$} \\
\hline DE-BBO & 2010 & Differential Evolution-Biogeography Based Optimization & {$[21]$} \\
\hline DHSPM & 2015 & $\begin{array}{l}\text { Dynamic Harmony Search with Polynomial Mutation } \\
\text { Algorithm }\end{array}$ & {$[58]$} \\
\hline DPSO-Sine & 2015 & Democratic PSO algorithm Endowed with Sine Chaotic Map & {$[14]$} \\
\hline DSPSO-TSA & 2010 & Hybrid Distributed Sobol PSO-TSA & {$[12]$} \\
\hline FAPSO-VDE & 2011 & $\begin{array}{l}\text { Fuzzy Adaptive PSO integrating-Variable Differential } \\
\text { Evolution }\end{array}$ & [19] \\
\hline FPA & 2016 & Flower Pollination Algorithm & {$[32]$} \\
\hline GA & 2010 & Genetic Algorithm & [12] \\
\hline $\mathrm{GrC}$ & 2019 & Granular Computing Method & [24] \\
\hline$\beta-G W O$ & 2019 & $\begin{array}{l}\text { Hybrid } \beta \text {-hill climbing optimizer with Grey Wolf } \\
\text { Optimization }\end{array}$ & {$[23]$} \\
\hline GWO & 2015 & Grey Wolf Optimization & [17] \\
\hline HCRO-DE & 2014 & $\begin{array}{l}\text { Hybrid Chemical Reaction Optimization with Differential } \\
\text { Evolution }\end{array}$ & {$[30]$} \\
\hline HS-BLO & 2015 & $\begin{array}{l}\text { Harmony Search Algorithm with Opposition-Based } \\
\text { Learning Techniques }\end{array}$ & [59] \\
\hline IACS & 2018 & Improved Artificial Cooperative Search Algorithm & {$[27]$} \\
\hline IFEP & 2003 & Improved Fast Evolutionary Programming & {$[10]$} \\
\hline ISA & 2018 & Interior Search Algorithm & [31] \\
\hline ITHS & 2013 & Intelligent Tuned Harmony Search Algorithm & [56] \\
\hline IWO & 2016 & Invasive Weed Optimization & {$[16]$} \\
\hline MBC-DE & 2019 & Multi-Behavior Combination with DE & {$[25]$} \\
\hline MP-CJAYA & 2018 & Multi-Population based Chaotic JAYA algorithm & [28] \\
\hline MVMOS & 2015 & Mean-Variance Mapping Optimization Swarm & [13] \\
\hline NGHS & 2016 & Natural Global-worst Harmony Search & [55] \\
\hline NPHS & 2016 & Natural Proportional Harmony Search & {$[55]$} \\
\hline NTHS & 2016 & Natural Tournament Harmony Search & [55] \\
\hline OGSA & 2012 & Opposition-based Gravitational Search Algorithm & [33] \\
\hline PSO-SQP & 2004 & $\begin{array}{l}\text { Particle Swarm Optimization-Sequential Quadractic } \\
\text { Programming }\end{array}$ & {$[18]$} \\
\hline PSF-HS & 2013 & Parameter-Setting-Free Harmony Search Algorithm & {$[60]$} \\
\hline PVHS & 2011 & Population-Variance Harmony Search Algorithm & [57] \\
\hline VCF_PSO & 2015 & $\begin{array}{l}\text { Varying Constriction Factor based Particle Swarm } \\
\text { Optimization }\end{array}$ & {$[20]$} \\
\hline
\end{tabular}




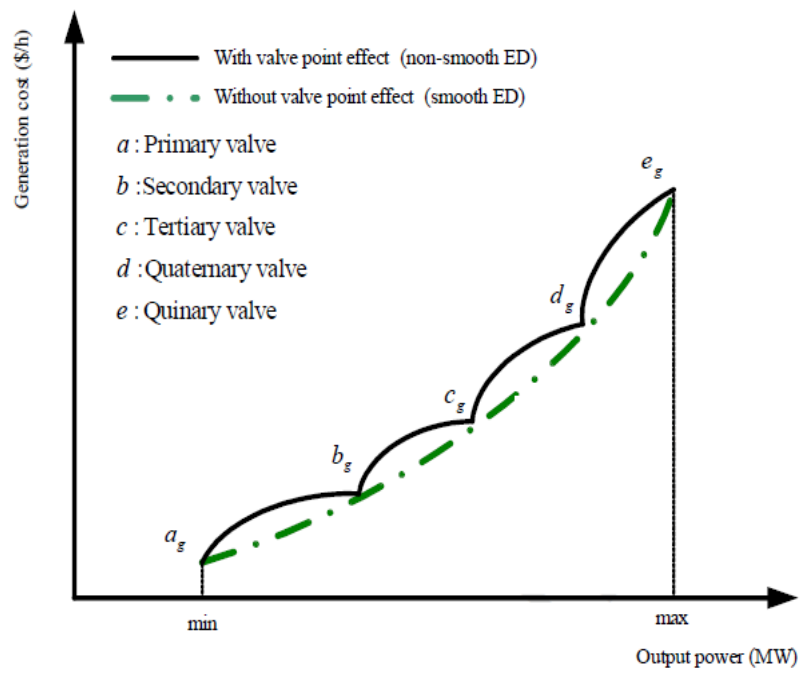

Figureure 1. Fuel cost curve of single fuel option considering five-valve steam turbine unit.

\section{Brief description of HS algorithm}

HSA is a metaheuristic technique that is given great ideas from the process of music players to accomplish better harmony, originally proposed by Geem et al in 2001 [35].

The HS method's key steps can be described as [35]:

Step 1: Initialization. Set parameters of HS, The main parameters of the HSA include [48]:

- Harmony memory size (HMS), where the population is memorized.

- Pitch adjusting rate (PAR) for a new generated harmony, with PAR $\in[0,1]$,

- Harmony memory considering rate (HMCR), with HMCR $\in[0,1]$,

- Bandwidth (BW) for pitch adjustment, number of improvisations (NI) and number of maximum iterations (Nmax).

Minimize $f(x)$,

S. $\mathrm{t}$

$$
L B_{i} \leq x_{i} \leq U B_{i}, \quad i \in[1, N] .
$$

Where, $f(x)$ is the objective function, $x_{i}$ is the solution vector of the HMS, $L B_{i}$ and $U B_{i}$ are the minimum and maximum values of $x_{i}$.

Step 2. Initialization of the HM matrix

HM is initialized by randomly produced harmony vectors considering HMS [52] by using Eq. (10) :

$$
x_{i}^{j}=L B_{i}+\operatorname{rand}() \times\left(U B_{i}-L B_{i}\right) .
$$

where $j=1,2, \ldots$, HMS and rand () is random number, uniformly distributed between 0 and 1 . The HM matrix can be expressed as follow:

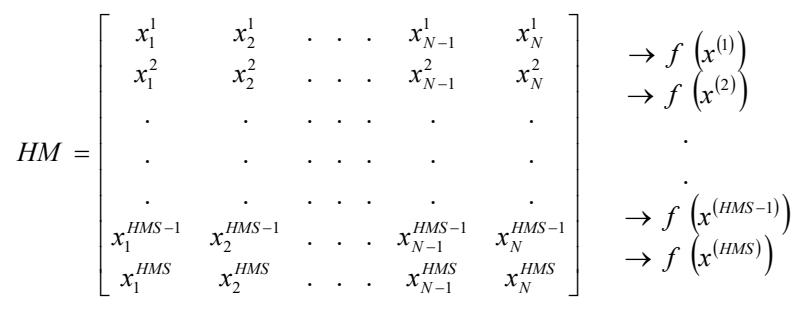




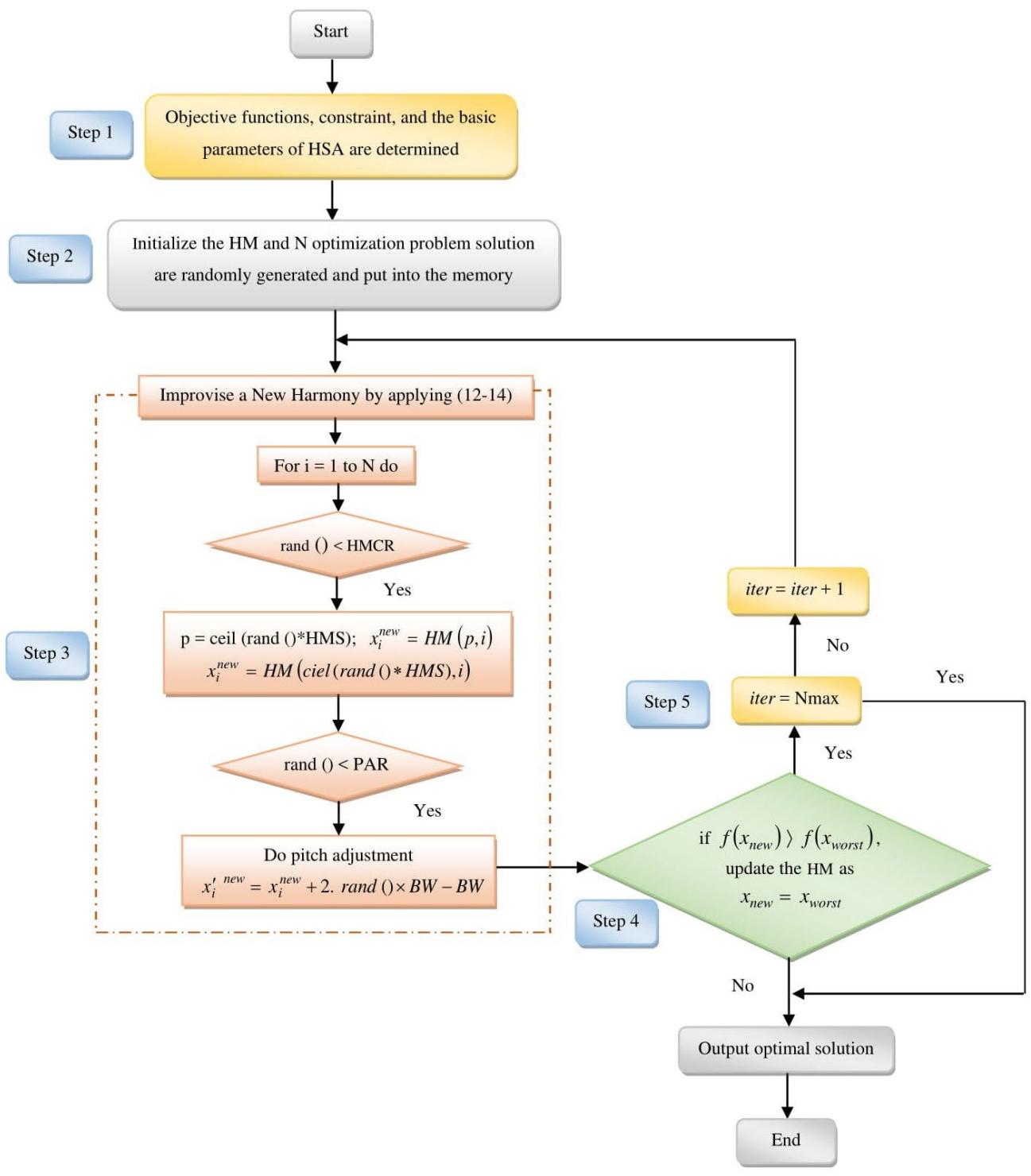

Figureure 2. A simplified flowchart of the HS algorithm.

Step 3. Improvise of a new harmony.

A novel solution vector $x_{i}^{n e w}=\left(x_{1}^{n e w}, 2_{2}^{n e w}, \ldots, N=\right.$ new $)$, is generated based on the main HS operators HMCR, PAR and BW. These operators are introduized in production of a new solution as the following [34]:

HMCR,

$$
x_{i}^{\text {new }} \leftarrow\left\{\begin{array}{l}
x_{i}^{\text {new }} \in\left\{x_{i}^{1}, x_{i}^{2}, \ldots, x_{i}^{H M S}\right\}, \text { with probability } H M C R \\
x_{i}^{\text {new }} \in X_{i}, \quad \text { otherwise }: i=1,2, \ldots, N .
\end{array}\right.
$$

PAR,

$$
x_{i}^{\text {new }} \leftarrow\left\{\begin{array}{l}
\text { Yes with probability } P A R \\
\text { No with probability }(1-P A R)
\end{array}\right.
$$


A new solution vector $x_{i}$ based on the disturbance principle can be generated as follows [63]:

$$
x_{i}^{\prime}{ }^{\text {new }}=x_{i}^{\text {new }}+2 \operatorname{rand}() \times B W-B W
$$

$x_{i}^{\prime \text { new }}$ is the $i^{\text {th }}$ new solutions after disturbance.

Step 4. Updating the new harmony. The new harmony will replace the worst if $f\left(x_{\text {new }}\right)<f\left(x_{\text {worst }}\right)$.

Step 5. (Checking the stopping criterion). Repeat Step 3 and 4 until the Nmax is reached. A simplified flowchart of the HS method is demonstrated in Figure.2.

\section{Self-Adaptative Improved Harmony Search (SIHS) algorithm}

A. The motivation of the SIHS algorithm

Parameter settings have a massive effect at the performance of the HS algorithm. The PAR and BW operators, determining the accuracy of the solution. A small BW and low PAR values, becomes the convergence velocity of HSA very slowly and the first-rate-tuning of solution vectors could be increasing [49]. What's more, a bigger PAR and extensive BW values in the early iteration, HSA will converge fast to the satisfactory solution. Hence, may be very vital that PAR and BW had been dynamically adjusting at each new generation.

In SIHS algorithm, the precept concept is to use a wider BW to search in the whole domain and dynamically regulate the BW towards the best solution [44].

\section{B. Novel parameter of $B W$}

In this subsection, the self-adaptative improved HS algorithm with a changing bandwidth (BW) will be studied. Dynamic BW (DBW) is represented as a decreasing function of the current generation (iter) and of maximum iteration number (Nmax) specified for the problem, i.e. in the beginning phases of SIHS algorithm, BW is dynamically updating by maintaining a higher value and progressively reducing through a low value to ensure near convergence of the best solution [44].

The choice of the termination condition depends on the desired high quality level of the solution [44]. According to the criteria mentioned above, we find that the equation of a lowpass filter is approximately close to the requirement.

The new BW equation can be formulated as follows:

$$
B W(i)=\frac{h}{1+\gamma \cdot\left(\frac{i t e r}{N_{\max }}\right)^{\alpha}}
$$

where $h$ and $\gamma$ are constant values depend on the limit of BW values. To satisfy the abovementioned criteria, generally $h$ takes the value of BWmax and the exponent $\alpha$ must be greater than 1 .

$$
\begin{aligned}
& \text { if } \sum_{i}^{N} P_{i}\left\langle P_{D} \text {, Add an amount } \varepsilon\right. \\
& \varepsilon \leftarrow\left|\sum_{i}^{N} P_{i}-P_{D}\right| \text { to } P_{i}^{\text {new }} \text { that doesn't violate } P_{i}^{\max }, \text { such as } P_{i}^{\text {new }} \leftarrow \min \left(P_{i}^{\text {new }}+\varepsilon, P_{i}^{\max }\right) \\
& \text { else if } \left.\sum_{i}^{N} P_{i}\right\rangle P_{D}, \text { Subtract an amount } \varepsilon \\
& \varepsilon \leftarrow\left|\sum_{i}^{N} P_{i}-P_{D}\right| \text { to } P_{i}^{\text {new }} \text { that doesn't violate } P_{i}^{\text {min }} \text {, such as } P_{i}^{\text {new }} \leftarrow \max \left(P_{i}^{\text {new }}-\varepsilon, P_{i}^{\text {min }}\right)
\end{aligned}
$$

Figureure 3. Flowchart of constraints handling used HS and SIHS algorithms.

According to [44], a fairly truthful result may be obtained whilst BWmin value must be very small, normally $\sim 0.1 \%$ of the range of decision variables. While BWmax is assumed to 
Boudjella Houari, et al.

$5 \sim 10 \%$ of the variety of dimension problem. The value of $\gamma$, is evaluated with the logarithmic decremental equation as follow:

$$
\gamma=b_{1} \times \ln \left(\frac{B W_{\text {max }}}{b_{2} \times B W_{\min }}\right)
$$

where $b_{1}$ and $b_{2}$ are constants and their values are experimentally determined in [44], [64], the best values of $b_{1}$ and $b_{2}$ that gives a minimum BW value ensures precise and fast convergence towards the optimal solution are chosen at 50 and 100 , respectively.

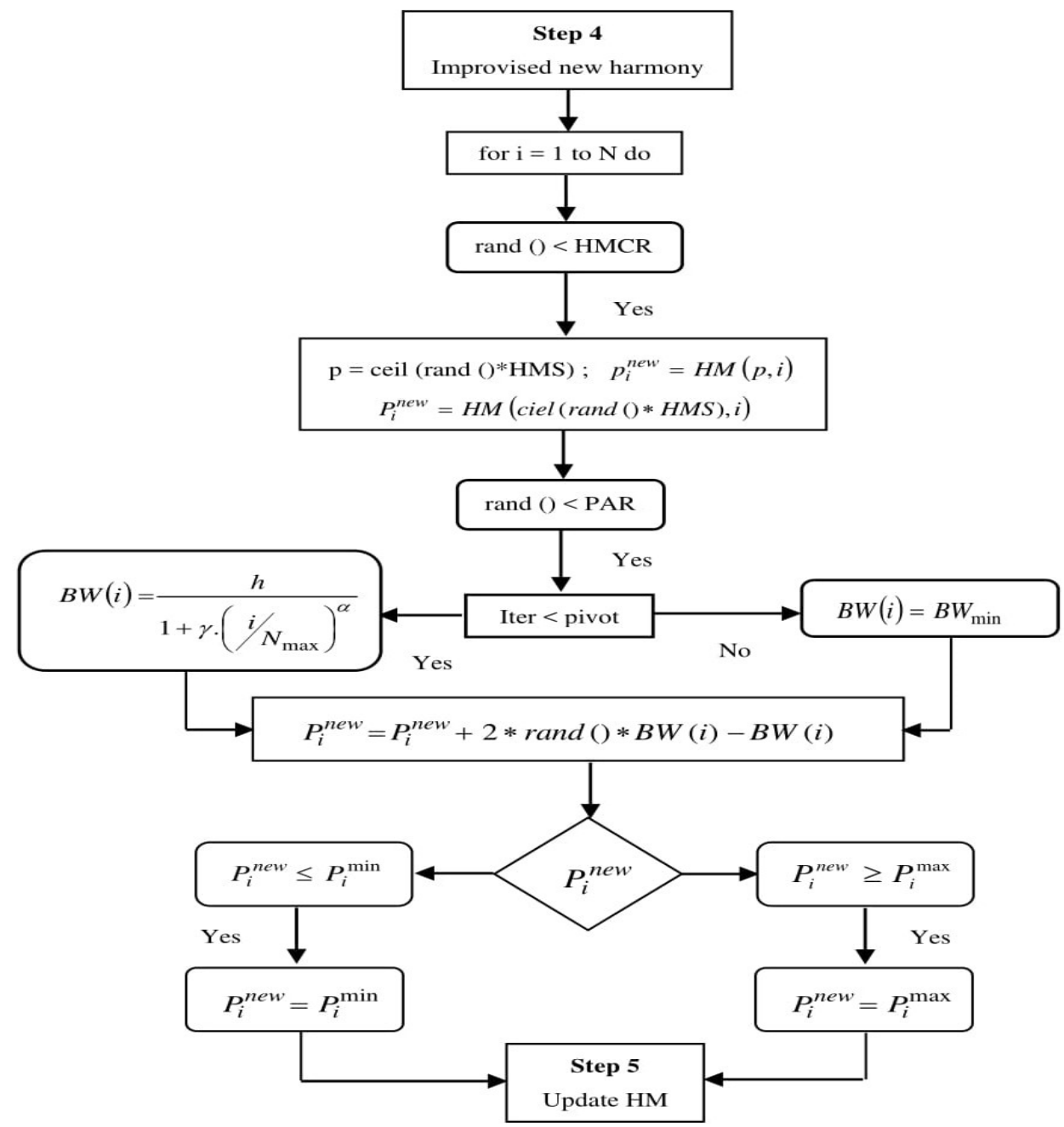

Figureure 4. Process of improvisation new harmony in SIHS algorithm

For the problems having low decision variables, Eq. (15) is more efficient to compute dynamic BW. For highly complex optimization problems, the best solution is found by modified Eq. (15) to a discontinuous adaptative dynamic BW function [44]. The proposed DADBW function is expressed as:

$$
B W(i)= \begin{cases}B W(i)=\frac{h}{1+\gamma\left(i t e r / N_{\max }\right)^{\alpha} ;} & i<\text { pivot } \\ B W_{\min } & ; \quad i \geq \text { pivot }\end{cases}
$$


Where, 'pivot' decides the optimum point where the BW changes (generally $\mathrm{N}_{\max } / 2$ ).

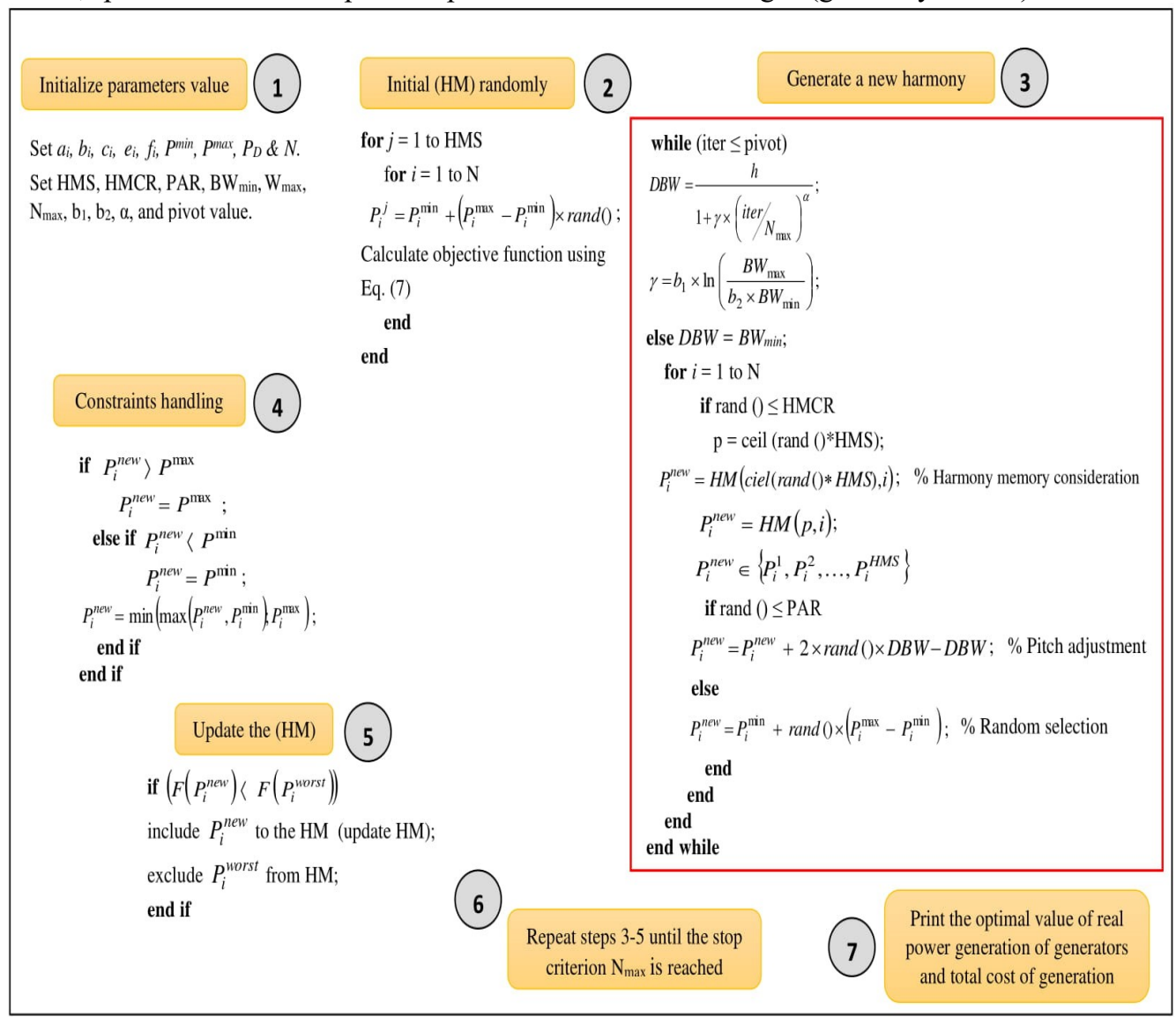

Figureure 5: Pseudo code of SIHS algorithm to ED problem

\section{Implementation of SIHS algorithm to solved ED problems}

In this part, the SIHS algorithm is used for solving ELD problems with thinking about load demand effect (VPE). Based on the similar improvement techniques, the proposed SIHS process is demonstrate under:

Step 1. Specify the generator cost coefficients $\left(a_{i}, b_{i}, c_{i}, e_{i}\right.$ and $\left.f_{i}\right)$, total number of generator units (N), set $P_{\max }$ and $P_{\min }$ of all units and load demand $\mathrm{P}_{\mathrm{D}}$. Set the parameters values of SIHS algorithm (HMS, HMCR, PAR, BW $\mathrm{max}_{\min }, \mathrm{BW}_{\min }, \mathrm{NI}, \mathrm{N}_{\max }$ and Pivot).

Step 2. Initialize HM matrix with size $(\mathrm{HMS} \times \mathrm{N})$. The initial $\mathrm{HM}$ is randomly generating as follow:

$$
H M(i, j)=P_{i}^{j}=P_{i}^{\min }+\operatorname{rand}() \times\left(P_{i}^{\max }-P_{i}^{\min }\right)
$$

Index of $j$ determines the $j^{\text {th }}$ generation unit. In order, to not violate the generator limits and not to operate at prohibited zone after each generation, the total power produced by all units is compared to power demand.

Figure. 3 present the process to checking equality constraint used in HS and SIHS algorithms. This process is iterated for other units until the $(\varepsilon=0)$.

Step 3. Calculate the fitness value for each solution vector in the HM matrix using Eq. (6). The HM matrix is represented by Eq. (11). 
Step 4. Generate a new solution by using Eq. (14) as mentioned in section (3) by changing BW value utilized Eq. (16). The process of a new harmony improvisation is depicted by the flowchart shown in Figure 4.

Step 5. Update the HM vector and calculate the fitness value $f\left(P_{G}\right)$, $P_{i}^{n e w}=\left(P_{1}^{n e w}, P_{2}^{n e w}, \ldots, P_{N}^{n e w}\right)$. The new real power generation of units will replace the worst $\left(P_{i}^{\text {new }}=P_{i}^{\text {worst }}\right)$ if $f\left(P_{i}^{\text {new }}\right)<f\left(P_{i}^{\text {worst }}\right)$.

Step 6. If $\mathrm{N}_{\max }$ is attained, go to Step 7; otherwise, repeat steps 4-5.

Step 7. Print the optimal value of active power generation of generators, thus the best total cost of production.

\section{Simulation results and discussion}

In order to evaluate the robustness of the proposed SIHS algorithm in solving ELD problems, four case studies with VPE have been taken into consideration. The constraints involved are power balance constraint without considering transmission losses and generator operating limits constraint. The obtained results are compared with the optimization approaches cited in Table 1. ELD cases include:

- $\quad$ Case I: 3-unit system with $P_{D}=850 \mathrm{MW}$;

- $\quad$ Case II: 13 -unit system with $\mathrm{P}_{\mathrm{D}}=1800 \mathrm{MW}$;

- $\quad$ Case III: 13-unit system with $\mathrm{P}_{\mathrm{D}}=2520 \mathrm{MW}$;

- $\quad$ Case IV: 40-unit system with $\mathrm{P}_{\mathrm{D}}=10500 \mathrm{MW}$;

Table 2. Parameters of HS and SIHS for ELD cases.

\begin{tabular}{|l|c|c|c|c|c|c|c|c|}
\cline { 2 - 9 } \multicolumn{1}{c|}{} & \multicolumn{2}{c|}{ Case I } & \multicolumn{2}{c|}{ Case II } & \multicolumn{2}{c|}{ Case III } & \multicolumn{2}{c|}{ Case IV } \\
\hline Parameters & HS & SIHS & HS & SIHS & HS & SIHS & HS & SIHS \\
\hline HMS & 5 & 5 & 10 & 10 & 20 & 20 & 20 & 20 \\
\hline HMCR & 0.85 & 0.95 & 0.85 & 0.95 & 0.85 & 0.95 & 0.85 & 0.95 \\
\hline PAR & 0.30 & 0.45 & 0.30 & 0.85 & 0.30 & 0.85 & 0.30 & 0.99 \\
\hline BW & 0.01 & - & 0.01 & - & 0.01 & - & 0.01 & - \\
\hline BW $_{\min }$ & - & 0.003 & - & 0.001 & - & 0.001 & - & 0.001 \\
\hline BW $_{\max }$ & - & 0.15 & - & 0.5 & - & 0.5 & - & 0.5 \\
\hline NI & 30 & 30 & 50 & 50 & 50 & 50 & 100 & 100 \\
\hline
\end{tabular}

All the cases studies are execute in MATLAB 2017 under windows 8.1 on Intel Core(TM) i3-3110 CPU 2.40 GHz, with 4 GB RAM. The parameters values of HS and SIHS for all cases are indicate in Table 2. $\alpha, \mathrm{N}_{\max }$, and pivot values of SIHS algorithms are 3, 10000, and $45 \% . \mathrm{N}_{\max }$ respectively. The pseudo-code of SIHS algorithm to solve ELD problem is shown in Figure.5. The values of these parameters are determined after performing various experiments, which provide more exploratory power. Due to the stochastic characteristic of both HS and SIHS algorithms, 60 trial runs have been performed. 
Table 3. Optimal output power for three-unit system with different algorithms

\begin{tabular}{|c|c|c|c|c|c|c|c|}
\hline $\begin{array}{c}\text { Output } \\
\text { (MW) }\end{array}$ & ITHS & MVMO $^{\text {S }}$ & IWO & DHSPM & $\begin{array}{c}\text { MP- } \\
\text { CJAYA }\end{array}$ & HS & $\begin{array}{c}\text { Proposed } \\
\text { SIHS }\end{array}$ \\
\hline Pg1 & 300.2668 & 300.2669 & 300.267 & 300.12 & 350.2464 & 300.2668 & 300.2668 \\
\hline Pg2 & 149.7331 & 400.0000 & 149.733 & 149.88 & 400.0000 & 400.000 & 400.0000 \\
\hline Pg3 & 400.000 & 149.7331 & 400.000 & 400 & 99.7576 & 149.7331 & 149.7331 \\
\hline $\begin{array}{c}\text { TP } \\
\text { (MW) }\end{array}$ & 850 & 850 & 850 & 850 & 850.004 & 850 & 850 \\
\hline $\begin{array}{c}\text { TC } \\
(\$ / h r)\end{array}$ & 8234.0717 & 8234.0717 & 8234.07 & 8234.07 & $\mathbf{8 2 2 3 . 2 9}$ & 8234.0717 & 8234.07173 \\
\hline
\end{tabular}

TP presents the total active power output.

TC presents the total cost of production.

\section{A. Case I}

The first case study covers of three thermal units with an overall load demand of $850 \mathrm{MW}$. The required data of the test system are available in literature [10].

The optimal generation schedule of 3-units system along with the total fuel cost obtained by HS and SIHS over 60 runs, are compared with ITHS, MVMO , IWO, DHSPM and MPCJAYA in Table 3. The best results are highlighted in bold font.

Obviously, almost all the comparative methods get the same minimum fuel cost of 8234.07 $(\$ / h)$, except for MP-CJAYA, which generated the best solution of $8223.29(\$ / \mathrm{h})$.

The best, mean, max fuel cost, standard deviation and computational time achieved by HS and SIHS are depicts in Table 4. We can see that the proposed SIHS algorithm is better in terms of computation efficiency $(0.0661 \mathrm{~s})$ than other methods recently published in the literature. In addition, the standard deviation of HS (1.946 \$/hr) is less than SIHS $(2.331 \$ / \mathrm{hr})$. The best standard deviation of $0.00 \$ / \mathrm{hr}$ is provided by $\mathrm{MVMO}^{\mathrm{S}}$.

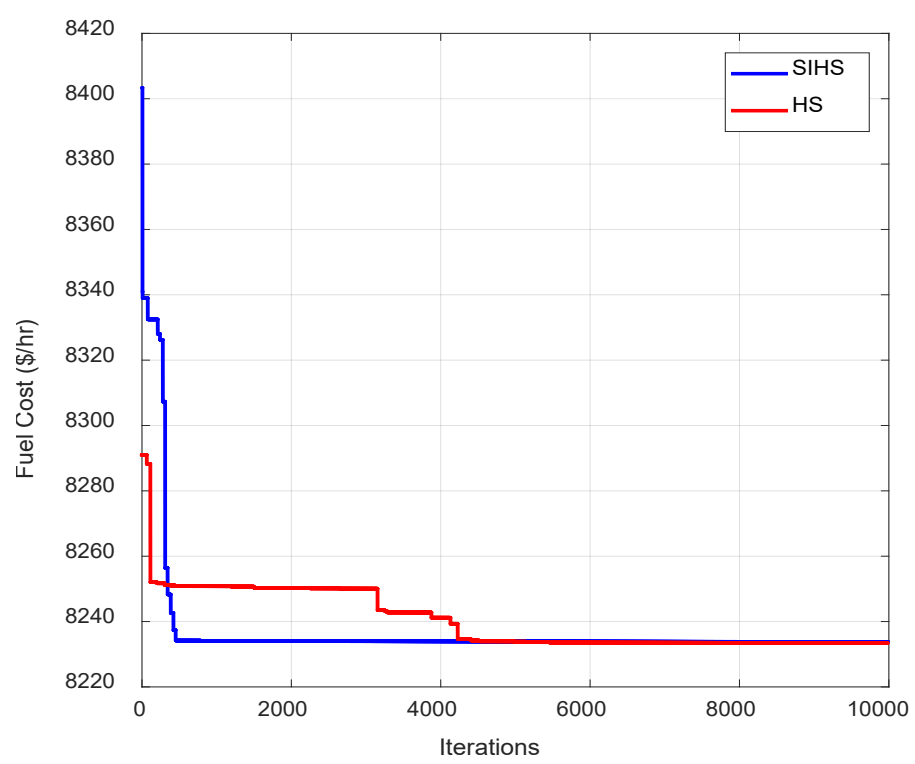

Figure 6. Fuel cost convergence behavior of case I. 
Boudjella Houari, et al.

Table 4. Comparison of simulation results of 3-units system with different algorithms

\begin{tabular}{|l|c|c|c|c|c|}
\hline \multicolumn{1}{|c|}{ Method } & $\begin{array}{c}\text { Best Fuel Cost } \\
(\$ / \mathrm{hr})\end{array}$ & $\begin{array}{c}\text { Mean Fuel Cost } \\
(\$ / \mathrm{hr})\end{array}$ & $\begin{array}{c}\text { Max Fuel Cost } \\
(\$ / \mathrm{hr})\end{array}$ & $\begin{array}{c}\text { Std. dev } \\
(\$ / \mathrm{hr})\end{array}$ & $\begin{array}{c}\text { CPU time } \\
(\mathrm{s})\end{array}$ \\
\hline MP-CJAYA & $\mathbf{8 2 2 3 . 2 9}$ & $\mathbf{8 2 3 2 . 0 6}$ & NA & NA & NA \\
\hline SIHS & 8234.07173 & 8234.9243 & 8241.1769 & 2.331 & $\mathbf{0 . 0 6 6 1}$ \\
\hline DHSPM & 8234.07 & 8234.09 & NA & NA & NA \\
\hline HS & 8234.07173 & 8234.6399 & 8241.17437 & 1.946 & 0.0672 \\
\hline ITHS & 8234.07175 & NA & NA & NA & NA \\
\hline MVMOS & 8234.0717 & 8234.0717 & 8234.0717 & $\mathbf{0 . 0 0 0 0}$ & 3.65 \\
\hline IWO & 8234.07 & 8236.97 & 8241.2 & NA & NA \\
\hline PSO-SQP & 8234.07 & 8234.07 & NA & NA & 3.37 \\
\hline NTHS & 8234.07 & 8234.07 & NA & NA & NA \\
\hline NGHS & 8234.07 & 8234.22 & NA & NA & NA \\
\hline NPHS & 8234.07 & 8234.08 & NA & NA & NA \\
\hline VCF_PSO & 8234.072 & 8258.727 & 8343.945 & 38.863 & 0.146 \\
\hline
\end{tabular}

NA means not available in the corresponding literature.

The fuel cost convergence obtained by HS and SIHS algorithms for 3-unit ELD problems is depict in Figure. 6. We see that SIHS has an incredible fast convergence ability compared to HS. SIHS has been trapped into local optimum at about 1201 iterations and HS at about 4526 iterations. Figure. 7 displays the overall cost of fuel per algorithm.

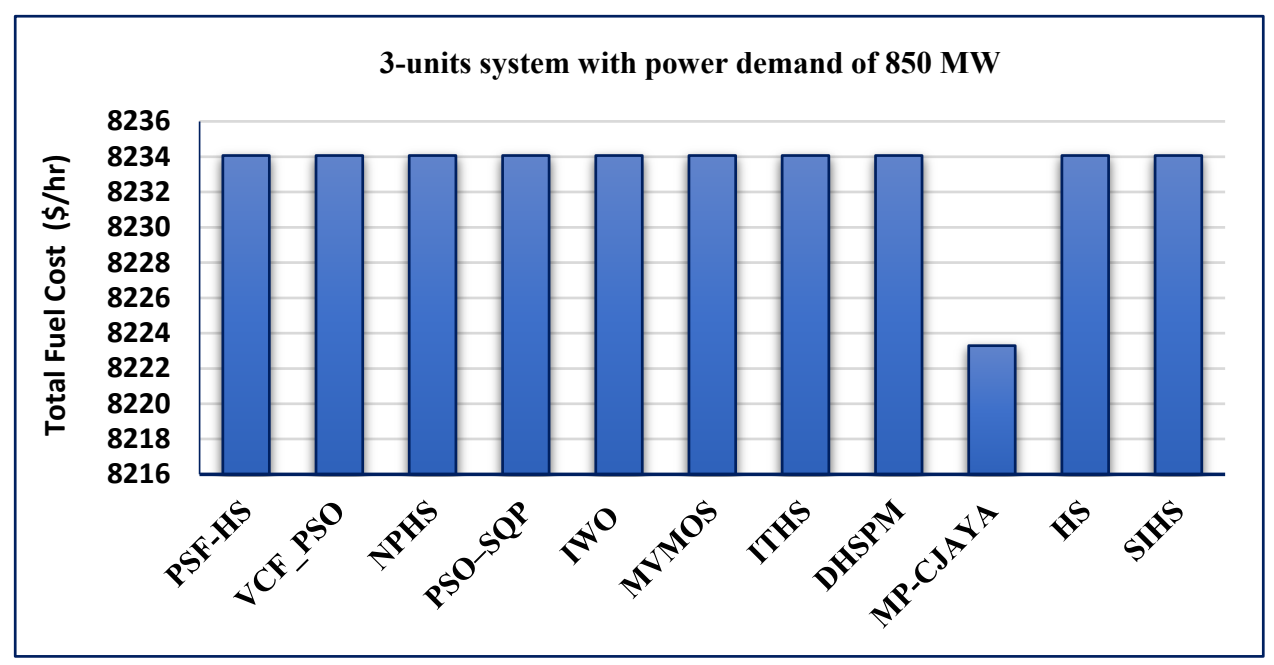

Figure 7. Total fuel cost for various methods for case study 1

B. Case II

The second case is a slightly wider system, comprising of 13 generators with a load demand of $1800 \mathrm{MW}$. The system data are extracted from [65].

The optimal real power dispatch and total cost obtained by various techniques such as DPSO-Sine, CBA, DHSPM, C-GRASP-SaDE, HS, and proposed SIHS are cited in Table 5. The best results are highlighted in bold font. The minimum value of TC achieved by HS and SIHS is $17960.442 \$ / \mathrm{hr}$ and $17961.576 \$ / \mathrm{hr}$ respectively. In this case study, the best TC is generated by C-GRASP-SaDE of $17960.393 \$ / \mathrm{hr}$. 


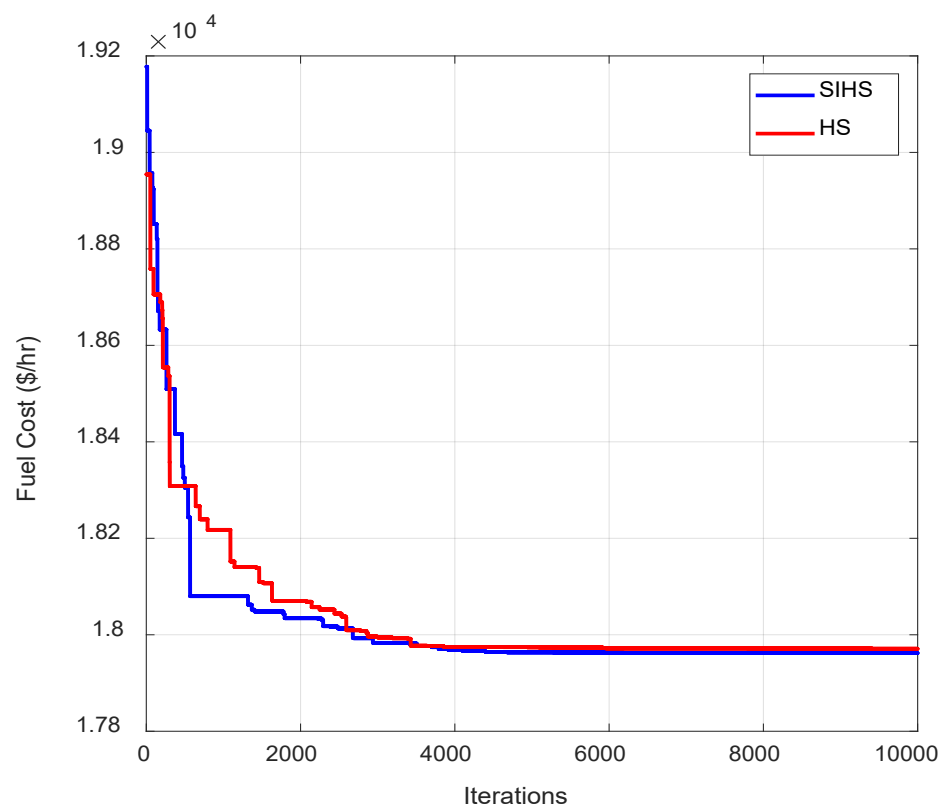

Figure 8. Fuel cost convergence behavior of 13-units system $\left(\mathrm{P}_{\mathrm{D}}=1800 \mathrm{MW}\right)$

Table 5. Best output power for 13-generator system with different algorithms $\left(\mathrm{P}_{\mathrm{D}}=1800 \mathrm{MW}\right)$

\begin{tabular}{|c|c|c|c|c|c|c|}
\hline $\begin{array}{c}\text { Output } \\
\text { (MW) }\end{array}$ & $\begin{array}{c}\text { DPSO- } \\
\text { Sine }\end{array}$ & CBA & DHSPM & $\begin{array}{c}\text { C-GRASP- } \\
\text { SaDE }\end{array}$ & HS & $\begin{array}{c}\text { Proposed } \\
\text { SIHS }\end{array}$ \\
\hline Pg1 & 628.31826 & 628.3185 & 628.3205 & 628.3185 & 628.231 & 628.318 \\
\hline Pg2 & 223.86847 & 149.5997 & 149.6024 & 149.5949 & 224.356 & 149.589 \\
\hline Pg3 & 148.98806 & 222.7491 & 222.7751 & 222.7571 & 148.292 & 222.775 \\
\hline Pg4 & 60.0000 & 109.8666 & 109.8655 & 109.8660 & 109.804 & 109.864 \\
\hline Pg5 & 109.42881 & 109.8666 & 109.8620 & 60.0000 & 109.780 & 109.865 \\
\hline Pg6 & 109.83620 & 109.8666 & 109.8582 & 109.8661 & 109.820 & 60.000 \\
\hline Pg7 & 109.83059 & 109.8666 & 60.0008 & 109.8662 & 109.862 & 109.858 \\
\hline Pg8 & 109.86588 & 60.0000 & 109.8614 & 109.8665 & 109.855 & 109.863 \\
\hline Pg9 & 109.86372 & 109.8663 & 109.8663 & 109.8665 & 60.000 & 109.865 \\
\hline Pg10 & 40.000 & 40.000 & 39.9997 & 40.0000 & 40.000 & 40.000 \\
\hline Pg11 & 40.000 & 40.000 & 39.9877 & 40.0000 & 40.000 & 40.000 \\
\hline Pg12 & 55.000 & 55.000 & 55.0001 & 55.0000 & 55.000 & 55.000 \\
\hline Pg13 & 55.000 & 55.000 & 55.0003 & 55.0000 & 55.000 & 55.000 \\
\hline TP $(\mathrm{MW})$ & 1800 & 1800 & 1800 & 1800 & 1800 & 1800 \\
\hline TC $(\$ / h r)$ & 17964.372 & 17963.83 & 17960.54 & $\mathbf{1 7 9 6 0 . 3 9 3}$ & 17961.576 & 17960.442 \\
\hline
\end{tabular}

Figure. 8 shows the best convergence behaviors of SIHS and HS. From Figure. 8, it is observed that SIHS converged to the optimum cost from 4390 iteration; it is quickly faster than HS (5982 iteration). The minimum cost of production obtained by each approach is offered in Figure. 9. Results of HS and SIHS have been compared with fifteen (15) methods reported in the literature, the results in terms of the maximum, mean, and best cost, standard deviation and mean computation time are summarized in Table 6. 
Boudjella Houari, et al.

Table 6. Comparison of simulation results for 13-generator system with different algorithms

\begin{tabular}{|c|c|c|c|c|c|}
\hline Method & $\begin{array}{c}\text { Best Fuel } \\
\text { Cost }(\$ / \mathrm{hr})\end{array}$ & $\begin{array}{l}\text { Mean Fuel } \\
\text { Cost }(\$ / h r)\end{array}$ & $\begin{array}{l}\text { Max Fuel } \\
\text { Cost }(\$ / h r)\end{array}$ & $\begin{array}{c}\text { Std. dev } \\
(\$ / \mathrm{hr})\end{array}$ & $\begin{array}{l}\text { CPU time } \\
\text { (s) }\end{array}$ \\
\hline C-GRASP-SaDE & 17960.393 & 17966.106 & 17968.868 & 2.701 & NA \\
\hline Proposed SIHS & 17960.442 & 17986.506 & 18066.928 & 36.205 & 0.0883 \\
\hline DHSPM & 17960.54 & 17994.16 & NA & NA & NA \\
\hline HS-BLO & 17960.6578 & 17969 & 18003 & 13.3525 & NA \\
\hline HS & 17961.576 & 18042.389 & 18134.100 & 36.199 & 0.0999 \\
\hline FAPSO-VDE & 17963.82 & 17963.82484 & 17963.832 & NA & NA \\
\hline $\mathrm{GrC}$ & 17963.8292 & 17963.8292 & 17963.8292 & 0.000 & 6 \\
\hline ACHS & 17963.8292 & 17973.7434 & 17978.1501 & 2.4877 & 0.93 \\
\hline CS-A & 17963.83 & 17965.05 & 17968.99 & 2.15 & NA \\
\hline CBA & 17963.83 & 17965.4889 & 17995.2256 & 6.8473 & 0.97 \\
\hline ANS & 17963.9031 & 17969.1487 & 17973.4437 & 3.0015 & NA \\
\hline MVMOS & 17964.1226 & 18011.0370 & 18070.7615 & 26.7448 & 34.02 \\
\hline DPSO- Sine & 17964.372 & 17973.049 & 17978.919 & 2.571 & NA \\
\hline IWO & 17968.00 & NA & NA & NA & NA \\
\hline PSO-SQP & 17969.93 & 18029.99 & NA & NA & 33.97 \\
\hline GWO & 17974.73 & 18085.49 & 18213.62 & NA & NA \\
\hline IFEP & 17994.07 & 18192.00 & 18416.89 & NA & 156.81 \\
\hline
\end{tabular}

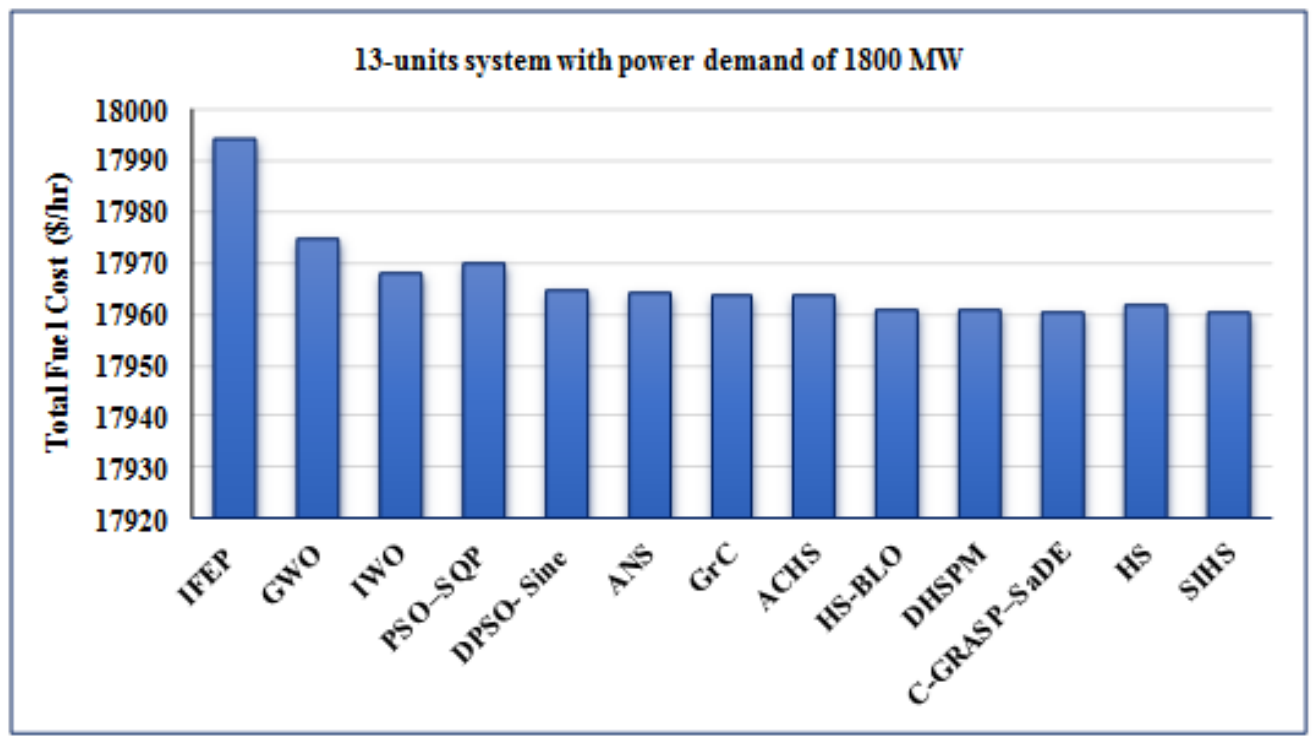

Figure 9. Total fuel cost for various methods for case study 2

\section{Case III}

The third case has the same number of generators and data as second case, expected different load demand of $2520 \mathrm{MW}$. All detailed data are available in [61].

The best power dispatch and best fuel cost solution obtained by SIHS and HS, are compared with those given by DPSO-Sine, MVMO , VCF-PSO, and IACS in Table 7. Notably, the optimal solution obtained is $24164.046 \$ / \mathrm{hr}$, it is achieved by IACS method, while the best cost obtained by the proposed SIHS is $24166.012(\$ / \mathrm{hr})$, which is comparatively less than other algorithms. 
Solution of Economic Load Dispatch Problems Using Novel Improved

Table 7. Best output power for 13-generator system with different algorithms $\left(P_{D}=2520 \mathrm{MW}\right)$

\begin{tabular}{|c|c|c|c|c|c|c|}
\hline $\begin{array}{c}\text { Output } \\
(\mathrm{MW})\end{array}$ & $\begin{array}{c}\text { DPSO- } \\
\text { Sine }\end{array}$ & MVMO $^{\text {S }}$ & VCF_PSO & IACS & HS & $\begin{array}{c}\text { Proposed } \\
\text { SIHS }\end{array}$ \\
\hline Pg1 & 628.317 & 628.345 & 628.319 & 628.318 & 628.320 & 628.278 \\
\hline Pg2 & 299.184 & 299.190 & 299.199 & 299.199 & 299.168 & 299.163 \\
\hline Pg3 & 299.190 & 299.192 & 299.199 & 294.482 & 295.507 & 295.000 \\
\hline Pg4 & 159.728 & 159.731 & 159.733 & 159.733 & 159.679 & 159.727 \\
\hline Pg5 & 159.732 & 159.729 & 159.733 & 159.733 & 159.743 & 159.722 \\
\hline Pg6 & 159.665 & 159.732 & 159.733 & 159.733 & 159.603 & 159.672 \\
\hline Pg7 & 159.727 & 159.731 & 159.733 & 159.733 & 159.649 & 159.625 \\
\hline Pg8 & 159.725 & 159.732 & 159.733 & 159.733 & 159.713 & 159.710 \\
\hline Pg9 & 159.728 & 159.707 & 159.733 & 159.733 & 159.707 & 159.741 \\
\hline Pg10 & 77.365 & 77.368 & 77.4 & 77.3999 & 114.333 & 77.347 \\
\hline Pg11 & 77.378 & 77.373 & 77.4 & 77.399 & 77.174 & 77.286 \\
\hline Pg12 & 87.905 & 92.362 & 92.394 & 92.399 & 55.000 & 92.435 \\
\hline Pg13 & 92.368 & 87.802 & 87.691 & 92.399 & 92.400 & 92.288 \\
\hline TP $(\mathrm{MW})$ & 2520 & 2520 & 2520 & 2520 & 2520 & 2520 \\
\hline TC $(\$ / h r)$ & 24170.015 & 24170.013 & 24169.934 & $\mathbf{2 4 1 6 4 . 0 4 6}$ & 24170.980 & 24166.012 \\
\hline
\end{tabular}

The best convergence characteristics of proposed SIHS and original HS compared with thirteen methods in the literature are included in Table 8.

Table 8. Comparison of simulation results for 13-generator system with different algorithms

\begin{tabular}{|c|c|c|c|c|c|}
\hline Method & $\begin{array}{c}\text { Best Fuel } \\
\text { Cost }(\$ / \mathrm{hr})\end{array}$ & $\begin{array}{l}\text { Mean Fuel } \\
\text { Cost }(\$ / h r)\end{array}$ & $\begin{array}{c}\text { Max Fuel } \\
\text { Cost }(\$ / \mathrm{hr})\end{array}$ & $\begin{array}{c}\text { Std. dev } \\
(\$ / \mathrm{hr})\end{array}$ & $\begin{array}{l}\text { CPU time } \\
\text { (s) }\end{array}$ \\
\hline IACS & 24164.046 & 24164.046 & 24164.046 & $2.45 \mathrm{E}-8$ & NA \\
\hline$\beta$-GWO & 24164.10 & 24164.20 & NA & 0.0492 & NA \\
\hline HCRO-DE & 24164.8260 & 24164.9837 & 24165.3402 & 0.058 & 5.04 \\
\hline Proposed SIHS & 24166.012 & 24308.278 & 24803.829 & 130.637 & 0.119 \\
\hline FAPSO-VDE & 24169.9176 & 24169.9176 & 24169.9176 & NA & NA \\
\hline ITHS & 24169.9218 & NA & NA & NA & NA \\
\hline DSPSO-TSA & 24169.923 & 24173.137 & 24230.803 & 7.72 & 2.92 \\
\hline VCF PSO & 24169.934 & 24306.784 & 24460.246 & 81.101 & 3.035 \\
\hline $\mathrm{MVMO}^{\mathrm{S}}$ & 24170.0137 & 24193.4933 & 24226.8256 & 23.6363 & 34.32 \\
\hline DPSO- Sine & 24170.015 & 24172.885 & 24176.515 & 1.994 & NA \\
\hline GA & 24170.804 & 24188.394 & 24567.974 & 59.53 & 19.39 \\
\hline HS & 24170.980 & 24288.556 & 24638.500 & 1.084 & 0.125 \\
\hline MP-CJAYA & 24175.5444 & 24228.1331 & NA & NA & NA \\
\hline $\mathrm{ACO}$ & 24195.91 & 24182.79 & 24169.63 & 7.86 & 14.35 \\
\hline PSO-SQP & 24261.05 & NA & NA & NA & NA \\
\hline
\end{tabular}

We can see from Table 8 that the minimum fuel cost of the proposed SIHS is comparatively lower than any other methods except for the IACS, $\beta$-GWO, and HCRO-DE performs significantly better than SIHS, but the results are competitive.

However, ICAS outperform all the other techniques in terms of best, mean, max fuel cost and standard deviation. The best computation time is provided by SIHS of $0.119 \mathrm{~s}$. Figure. 10 demonstrates the convergence behavior of the best total fuel cost obtained by the proposed SIHS and HS. It is clear that SIHS algorithm converge slowly to the best cost value; at about 8292 iteration and HS converge at about 9496 iteration. The best fuel cost obtained by every algorithm is illustrated in Figure. 11. 
Boudjella Houari, et al.

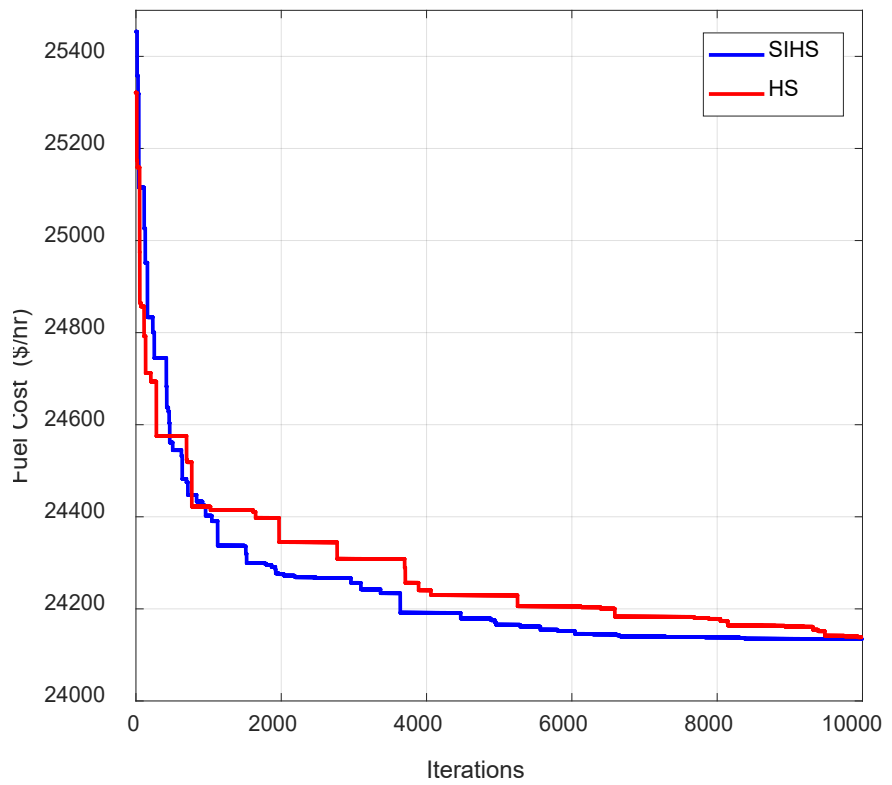

Figure 10. Fuel cost convergence behavior of 13-units system $\left(\mathrm{P}_{\mathrm{D}}=2520 \mathrm{MW}\right)$

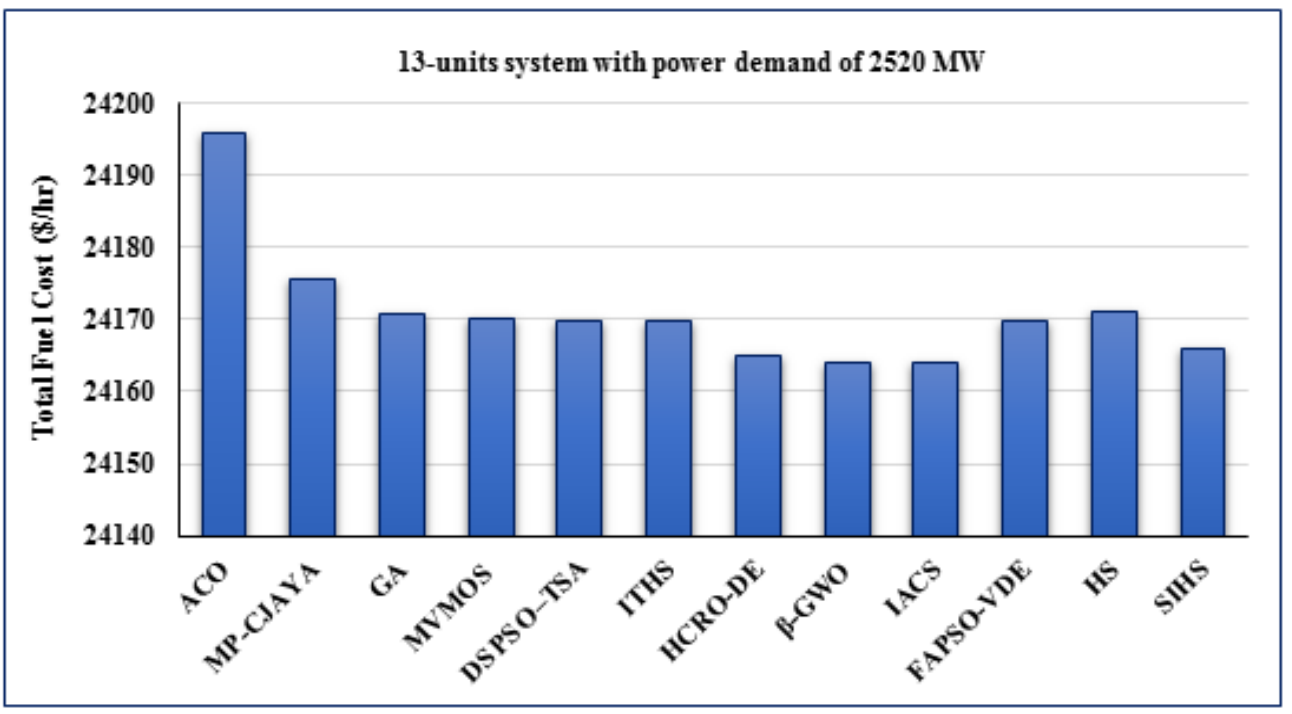

Figure 11. Total fuel cost for various methods for case study 3

D. Case IV

Due to 40 units with load demand of $10500 \mathrm{MW}$, and non-linearity of fuel cost functions due to VPE, test case 4 becomes more complex than the three cases studied above. The required data of case 4 are mainly derived from [10], [61].

To prove the efficiency of SIHS algorithm for large-scale economic dispatch of power systems, comparison results from methods ISA, OGSA, IACS, CIHSA, HS, and SIHS are illustrate in Table 9. 


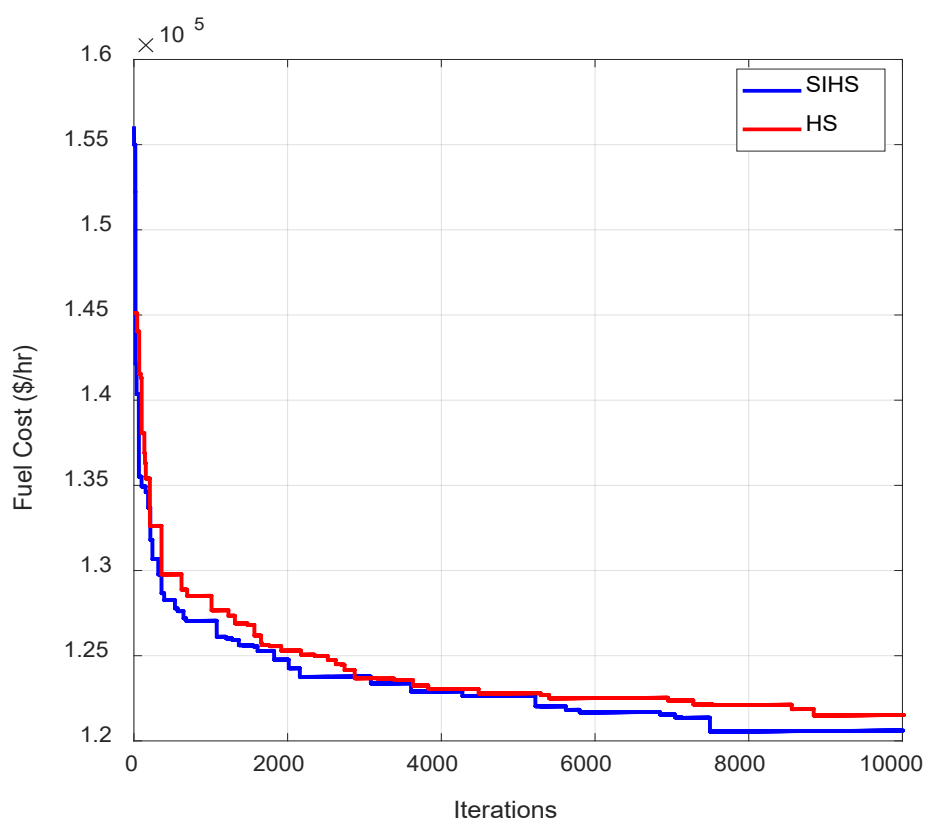

Figure 12. Fuel cost convergence behavior of 40-units system

The best statistical results of SIHS and HS algorithms compared with six HS variants technique and 19 methods mentioned in the literature, are recorded in Table 10. According to Table 10, the smallest fuel cost is obtained by the proposed SIHS of $120276.6778 \mathrm{\$} / \mathrm{hr}$. what is more, the lowest values of mean fuel cost and max fuel cost, are also achieved by SIHS, which is $120317.1410 \$ / \mathrm{hr}, 120340.0490 \$ / \mathrm{hr}$ respectively. The convergence curve of SIHS and HS are shown in Figure. 12. It is observed that the fuel cost function converges smoothly to the optimal solution without any abrupt oscillations, this proving the accuracy of the suggested algorithm.

Table 9. Best output power for 40-generator system with different algorithms

\begin{tabular}{|c|c|c|c|c|c|c|}
\hline $\begin{array}{c}\text { Output } \\
\text { (MW) }\end{array}$ & IACS & CIHSA & OGSA & ISA & HS & SIHS \\
\hline Pg1 & 110.8687 & 110.7998 & 114.0000 & 114.0004 & 114.0000 & 114.0000 \\
\hline Pg2 & 110.0013 & 110.7998 & 114.0000 & 111.1742 & 110.8045 & 114.0000 \\
\hline Pg3 & 97.3999 & 97.3999 & 120.0000 & 120.0000 & 97.4002 & 120.0000 \\
\hline Pg4 & 179.7331 & 179.7330 & 189.6786 & 188.5674 & 179.7335 & 189.7823 \\
\hline Pg5 & 92.4706 & 87.7999 & 97.0000 & 96.6566 & 87.8374 & 97.0000 \\
\hline Pg6 & 139.9999 & 140.0000 & 140.0000 & 139.9567 & 140.0000 & 139.8792 \\
\hline Pg7 & 259.5996 & 259.5996 & 259.2637 & 259.2432 & 259.5994 & 259.2633 \\
\hline Pg8 & 284.5996 & 284.5996 & 283.0360 & 282.9832 & 284.6007 & 282.9224 \\
\hline Pg9 & 284.5996 & 284.5996 & 290.0689 & 290.0129 & 284.6001 & 290.0191 \\
\hline Pg10 & 130.0000 & 130.0000 & 130.0000 & 129.8653 & 130.0000 & 129.8827 \\
\hline Pg11 & 168.7998 & 94.0000 & 101.2163 & 100.1766 & 168.7995 & 102.3883 \\
\hline Pg12 & 168.7998 & 94.0000 & 153.6064 & 153.6031 & 168.7997 & 153.5809 \\
\hline Pg13 & 214.7597 & 214.7597 & 210.1281 & 209.8476 & 214.7594 & 210.0005 \\
\hline Pg14 & 394.2793 & 394.2793 & 305.2207 & 305.1765 & 304.9195 & 305.2086 \\
\hline Pg15 & 394.2793 & 394.2793 & 297.6248 & 297.5324 & 394.2584 & 297.6197 \\
\hline Pg16 & 304.5195 & 394.2793 & 212.8865 & 211.8546 & 394.2791 & 212.8017 \\
\hline Pg17 & 489.2793 & 489.2793 & 499.7336 & 198.7546 & 489.2793 & 499.7881 \\
\hline Pg18 & 489.2793 & 489.2793 & 489.4927 & 488.8563 & 489.2793 & 488.9471 \\
\hline Pg19 & 511.2793 & 511.2793 & 511.9556 & 511.5464 & 511.3765 & 511.2171 \\
\hline
\end{tabular}


Boudjella Houari, et al.

\begin{tabular}{|c|c|c|c|c|c|c|}
\hline $\begin{array}{c}\text { Output } \\
\text { (MW) }\end{array}$ & IACS & CIHSA & OGSA & ISA & HS & SIHS \\
\hline Pg20 & 511.2793 & 511.2793 & 515.1468 & 514.1376 & 511.3765 & 514.9398 \\
\hline Pg21 & 523.2793 & 523.2793 & 524.8624 & 523.7647 & 523.5194 & 524.7284 \\
\hline Pg22 & 523.2793 & 523.2793 & 516.3822 & 515.9546 & 522.3888 & 515.8311 \\
\hline Pg23 & 523.2793 & 523.2793 & 522.0437 & 522.0176 & 523.2796 & 522.1840 \\
\hline Pg24 & 523.2793 & 523.2793 & 526.5253 & 526.5187 & 523.2794 & 526.2376 \\
\hline Pg25 & 523.2793 & 523.2793 & 512.1440 & 512.1322 & 523.2795 & 512.1179 \\
\hline Pg26 & 523.2793 & 523.2793 & 523.0461 & 523.0263 & 523.2795 & 523.1047 \\
\hline Pg27 & 10.0000 & 10.0000 & 131.8133 & 130.8563 & 10.0000 & 131.8415 \\
\hline Pg28 & 10.0000 & 10.0000 & 150.0000 & 149.8672 & 10.0000 & 149.9635 \\
\hline Pg29 & 10.0000 & 10.0000 & 133.4239 & 133.3567 & 10.0000 & 133.4329 \\
\hline Pg30 & 87.8169 & 87.7999 & 97.0000 & 97.0000 & 89.5070 & 97.0000 \\
\hline Pg31 & 189.9999 & 190.0000 & 187.6443 & 187.5767 & 190.0000 & 187.7540 \\
\hline Pg32 & 189.9999 & 190.0000 & 190.0000 & 190.0000 & 190.0000 & 190.0000 \\
\hline Pg33 & 189.9999 & 190.0000 & 169.7297 & 169.6498 & 189.9998 & 169.7165 \\
\hline Pg34 & 164.7998 & 164.7998 & 190.9535 & 190.8456 & 164.7514 & 190.9541 \\
\hline Pg35 & 164.7998 & 194.3978 & 176.4784 & 176.4638 & 164.9037 & 176.4723 \\
\hline Pg36 & 164.7998 & 199.9999 & 164.6995 & 164.4847 & 164.8296 & 164.6438 \\
\hline Pg37 & 109.9999 & 109.9999 & 99.1969 & 99.1254 & 110.0000 & 99.1597 \\
\hline Pg38 & 109.9999 & 110.0000 & 34.8100 & 32.4353 & 110.0000 & 34.8852 \\
\hline Pg39 & 109.9999 & 109.9999 & 85.8264 & 85.3543 & 109.9999 & 85.7163 \\
\hline Pg40 & 511.2793 & 511.2793 & 532.0793 & 530.7646 & 511.2794 & 531.0150 \\
\hline TP (MW) & 10500 & 10500 & 10500 & 10500 & 10500 & 10500 \\
\hline TC (\$/hr) & 121371.56 & 121412.53 & 120390.00 & 120385.47 & 121075.941 & $\mathbf{1 2 0 2 7 6 . 6 7}$ \\
\hline
\end{tabular}

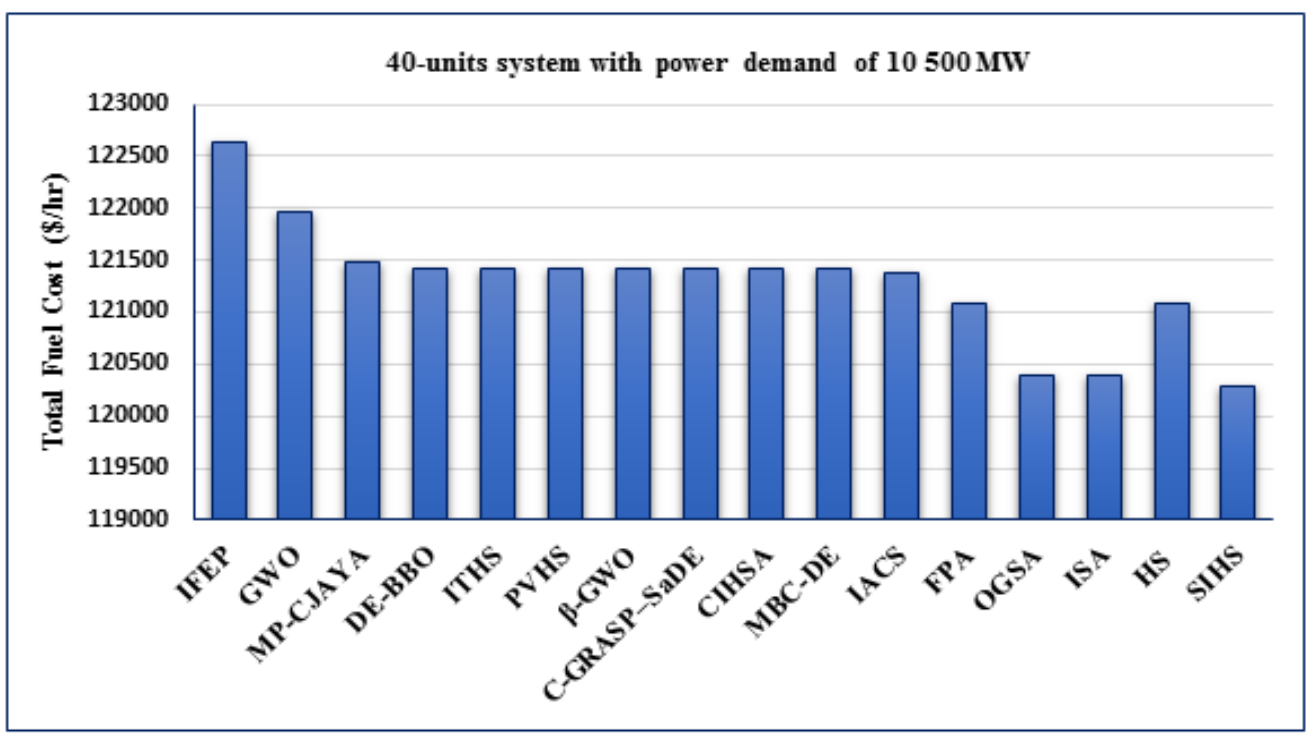

Figure 13. Total fuel cost for various methods for case study 4.

The minimum standard deviation of $0.0018 \$ / \mathrm{hr}$ is obtained by $\mathrm{GrC}$ in [24]. The smallest computation time is 0.06 (s), obtained by DE-BBO in [21]. SIHS has higher standard deviation of $486.8694 \$ / \mathrm{hr}$ and smaller CPU time of $0.2373(\mathrm{~s})$. 
Table 10. Comparison of simulation results for 13-generator system with different algorithms

\begin{tabular}{|l|c|c|c|c|c|}
\hline \multicolumn{1}{|c|}{ Method } & $\begin{array}{c}\text { Best Fuel } \\
\text { Cost }(\$ / \mathrm{hr})\end{array}$ & $\begin{array}{c}\text { Mean Fuel } \\
\text { Cost }(\$ / \mathrm{hr})\end{array}$ & $\begin{array}{c}\text { Max Fuel } \\
\text { Cost }(\$ / \mathrm{hr})\end{array}$ & $\begin{array}{c}\text { Std. dev } \\
(\$ / \mathrm{hr})\end{array}$ & $\begin{array}{c}\text { CPU time } \\
(\mathrm{s})\end{array}$ \\
\hline Proposed SIHS & $\mathbf{1 2 0 2 7 6 . 6 7 7 8}$ & $\mathbf{1 2 0 3 1 7 . 1 4 1 0}$ & $\mathbf{1 2 0 3 4 0 . 0 4 9 0}$ & 486.8694 & 0.237336 \\
\hline ISA & 120385.47 & 120403.21 & 120478.62 & NA & NA \\
\hline OGSA & 120390.00 & NA & NA & NA & NA \\
\hline FPA & 121074.500 & 121095.7 & 121196.3 & NA & 0.89 \\
\hline HS & 121075.941 & 121126.824 & 1211475.729 & 5.22012 & 0.2431 \\
\hline IACS & 121371.5603 & $121,423.33$ & $121,450.32$ & NA & NA \\
\hline GrC & 121412.5355 & 121412.5360 & 121412.5380 & $\mathbf{0 . 0 0 1 8}$ & 43 \\
\hline MBC-DE & 121412.5355 & 121450.32 & 121481.33 & 21.658087 & NA \\
\hline CIHSA & 121412.5365 & 121413.3736 & 121420.8962 & 2.5725 & NA \\
\hline CBA & 121412.5468 & 121418.9826 & 121436.15 & 1.611 & 1.55 \\
\hline HCRO-DE & 121412.55 & 121413.11 & 121415.68 & 0.13 & 7.64 \\
\hline ANS & 121412.6226 & 121427.7107 & 121472.9213 & 13.6539 & NA \\
\hline DHSPM & 121412.66 & 121423.57 & NA & NA & NA \\
\hline NTHS & 121412.7374 & 121549.95 & NA & NA & NA \\
\hline C-GRASP-SaDE & 121414.621 & 121736.025 & 122245.696 & 166.896 & NA \\
\hline ACHS & 121414.8587 & 121510.50 & 121655.66 & 54.28 & 2.18 \\
\hline$\beta-G W O$ & 121415.09 & 121417.79 & NA & 3.9476 & NA \\
\hline MVMO & 121415.2346 & 121652.7238 & $121,913.4278$ & 115.3685 & 107.98 \\
\hline PVHS & 121415.4560 & 121567.0292 & NA & 94.1498 & NA \\
\hline ITHS & 121416.6526 & 121416.7196 & 121417.025 & 0.1087 & NA \\
\hline DE-BBO & 121420.8948 & 121420.8952 & 121420.8963 & NA & $\mathbf{0 . 0 6}$ \\
\hline DPSO- Sine & 121424.0947 & 121459.909 & 121508.002 & 21.097 & NA \\
\hline MP-CJAYA & 121480.10 & 121861.08 & NA & NA & NA \\
\hline IWO & 121485.90 & NA & NA & NA & NA \\
\hline GWO & 121963.721 & 122731.166 & 123884.827 & NA & NA \\
\hline
\end{tabular}

The superiority of the proposed SIHS algorithm in reducing the total fuel cost value compared to other algorithms in literature can be confirmed as shown in Figure. 13.

As observed from Tables 3, 5, 7, and 9, the power output of each unit lies within the minimum and maximum generator capacity limits and satisfies the power balance constraint.

\section{CONCLUSIONS}

In this paper, solutions of ELD problem with VPE have been found by introduce an effective SIHS algorithm, which is developed based on conventional HS by generate a new harmony solution with dynamically varying bandwidth.

In order, to examine the efficacy and the robustness of the suggested SIHS algorithm, four typical ELD cases are employed without considering transmission losses. The numerical findings confirm that the SIHS can provide better solutions with lowest computation time than other different metaheuristic optimization, and successfully improve the efficiency of the ELD problems. However, the SIHS algorithm also has the weakness, that it requires "proper and appropriate" value setting for algorithm parameters.

From the evaluation above, it can be conclude that SIHS algorithm has the strongest ability of handling larger scale of ELD with several constraint. SIHS algorithm has demonstrate its superiority over all comparative methods in literature.

To ensure good results, in the future, we will endeavor to find a parameter-free developed technique combined with the SIHS algorithm and introduce it to other kinds of optimization issues, such as multi-objective ED problems with many complex constraints, dynamic ED problems and large-scale ELD problems integrated renewable energy sources. 


\section{7. acknowledgment}

This work was partially supported by the sustainable development laboratory of electrical energy (LDDEE), USTO-MB, Oran, Algeria; with cooperation of Laboratory of Energy and Electrical Systems, ENSEM, Hassan II University, Casablanca, Morocco.

\section{References}

[1] A. J. Wood, B. F. Wollenberg, and G. B. Sheblé, Power generation, operation, and control. John Wiley \& Sons, 2013.

[2] W. Ongsakul and V. N. Dieu, Artificial intelligence in power system optimization. Crc Press, 2013.

[3] G. Abbas, J. Gu, U. Farooq, M. U. Asad, and M. El-Hawary, "Solution of an economic dispatch problem through particle swarm optimization: a detailed survey-part I," IEEE Access, vol. 5, pp. 15105-15141, 2017.

[4] A. A. El-Keib, H. Ma, and J. L. Hart, "Environmentally constrained economic dispatch using the Lagrangian relaxation method," IEEE Trans. Power Syst., vol. 9, no. 4, pp. 1723-1729, 1994.

[5] B. H. Chowdhury and S. Rahman, "A review of recent advances in economic dispatch," IEEE Trans. power Syst., vol. 5, no. 4, pp. 1248-1259, 1990.

[6] J.-Y. Fan and L. Zhang, "Real-time economic dispatch with line flow and emission constraints using quadratic programming," IEEE Trans. Power Syst., vol. 13, no. 2, pp. 320-325, 1998.

[7] A. Farag, S. Al-Baiyat, and T. C. Cheng, "Economic load dispatch multiobjective optimization procedures using linear programming techniques," IEEE Trans. Power Syst., vol. 10, no. 2, pp. 731-738, 1995.

[8] Z.-X. Liang and J. D. Glover, "A zoom feature for a dynamic programming solution to economic dispatch including transmission losses," IEEE Trans. Power Syst., vol. 7, no. 2, pp. 544-550, 1992.

[9] D. C. SECUI, G. Bendea, and H. Cristina, "A modified harmony search algorithm for the economic dispatch problem," Stud. Informatics Control, vol. 23, no. 2, p. 144, 2014.

[10] N. Sinha, R. Chakrabarti, and P. K. Chattopadhyay, "Evolutionary programming techniques for economic load dispatch," IEEE Trans. Evol. Comput., vol. 7, no. 1, pp. 8394, 2003.

[11] S. Pothiya, I. Ngamroo, and W. Kongprawechnon, "Ant colony optimisation for economic dispatch problem with non-smooth cost functions," Int. J. Electr. Power Energy Syst., vol. 32, no. 5, pp. 478-487, 2010.

[12] S. Khamsawang and S. Jiriwibhakorn, "DSPSO--TSA for economic dispatch problem with nonsmooth and noncontinuous cost functions," Energy Convers. Manag., vol. 51, no. 2, pp. 365-375, 2010.

[13] T. H. Khoa, P. M. Vasant, M. S. B. Singh, and V. N. Dieu, "Solving economic dispatch problem with valve-point effects using swarm-based mean--variance mapping optimization (MVMOS)," Cogent Eng., vol. 2, no. 1, p. 1076983, 2015.

[14] D. C. Secui, D. Dumitrescu, and S. Bunda, "DEMOCRATIC PSO ALGORITHM FOR THE ECONOMIC DISPATCH PROBLEM WITH VALVE-POINT EFFECTS.," $J$. Sustain. Energy, vol. 6, no. 3, 2015.

[15] M. W. Mustafa, A. M. Abdilahi, and M. Mustapha, "Chaos-Enhanced Cuckoo Search for Economic Dispatch with Valve Point Effects," Telkomnika, vol. 14, no. 4, p. 1220, 2016.

[16] V. R. BHARADWAJ and G. SIDDHARTHA, "Invasive weed optimization for economic dispatch with valve point effects," J. Eng. Sci. Technol., vol. 11, no. 2, pp. 237-251, 2016.

[17] S. Sharma, S. Mehta, and N. Chopra, "Grey wolf optimization for solving non-convex economic load dispatch," Eng. Res., vol. 3, no. 3, pp. 17-21, 2015.

[18] T. A. A. Victoire and A. E. Jeyakumar, "Hybrid PSO--SQP for economic dispatch with valve-point effect," Electr. Power Syst. Res., vol. 71, no. 1, pp. 51-59, 2004. 
[19] T. Niknam, H. D. Mojarrad, and H. Z. Meymand, "A novel hybrid particle swarm optimization for economic dispatch with valve-point loading effects," Energy Convers. Manag., vol. 52, no. 4, pp. 1800-1809, 2011.

[20] M. N. Alam, K. Kumar, and A. Mathur, "Economic load dispatch considering valve-point effects using time varying constriction factor based particle swarm optimization," in 2015 IEEE UP Section Conference on Electrical Computer and Electronics (UPCON), 2015, pp. 1-6.

[21] A. Bhattacharya and P. K. Chattopadhyay, "Hybrid differential evolution with biogeography-based optimization for solution of economic load dispatch," IEEE Trans. power Syst., vol. 25, no. 4, pp. 1955-1964, 2010.

[22] J. X. V. Neto, G. Reynoso-Meza, T. H. Ruppel, V. C. Mariani, and L. dos Santos Coelho, "Solving non-smooth economic dispatch by a new combination of continuous GRASP algorithm and differential evolution," Int. J. Electr. Power Energy Syst., vol. 84, pp. 1324, 2017.

[23] M. A. Al-Betar, M. A. Awadallah, and M. M. Krishan, "A non-convex economic load dispatch problem with valve loading effect using a hybrid grey wolf optimizer," Neural Comput. Appl., pp. 1-28, 2019.

[24] X. Li, A. Li, and Z. Lu, "A Granular Computing Method for Economic Dispatch Problems With Valve-Point Effects," IEEE Access, vol. 7, pp. 78260-78273, 2019.

[25] J. Zhang and Z. Dong, "A general intelligent optimization algorithm combination framework with application in economic load dispatch problems," Energies, vol. 12, no. 11, p. $2175,2019$.

[26] G. Xiong et al., "A novel method for economic dispatch with across neighborhood search: a case study in a provincial power grid, China," Complexity, vol. 2018, 2018.

[27] O. E. Turgut, "International Journal of Intelligent Systems and Applications in Engineering," 2018.

[28] J. Yu, C.-H. Kim, A. Wadood, T. Khurshiad, and S.-B. Rhee, “A novel multi-population based chaotic JAYA algorithm with application in solving economic load dispatch problems," Energies, vol. 11, no. 8, p. 1946, 2018.

[29] B. R. Adarsh, T. Raghunathan, T. Jayabarathi, and X.-S. Yang, "Economic dispatch using chaotic bat algorithm," Energy, vol. 96, pp. 666-675, 2016.

[30] P. K. Roy, S. Bhui, and C. Paul, "Solution of economic load dispatch using hybrid chemical reaction optimization approach," Appl. Soft Comput., vol. 24, pp. 109-125, 2014.

[31] N. Karthik, A. K. Parvathy, and R. Arul, "Multi-objective economic emission dispatch using interior search algorithm," Int. Trans. Electr. Energy Syst., vol. 29, no. 1, p. e2683, 2019.

[32] A. Y. Abdelaziz, E. S. Ali, and S. M. Abd Elazim, "Implementation of flower pollination algorithm for solving economic load dispatch and combined economic emission dispatch problems in power systems," Energy, vol. 101, pp. 506-518, 2016.

[33] B. Shaw, V. Mukherjee, and S. P. Ghoshal, "A novel opposition-based gravitational search algorithm for combined economic and emission dispatch problems of power systems," Int. J. Electr. Power Energy Syst., vol. 35, no. 1, pp. 21-33, 2012.

[34] Z. W. Geem, "Optimal cost design of water distribution networks using harmony search," Eng. Optim., vol. 38, no. 03, pp. 259-277, 2006.

[35] Z. W. Geem, J. H. Kim, and G. V. Loganathan, "A new heuristic optimization algorithm: harmony search," Simulation, vol. 76, no. 2, pp. 60-68, 2001.

[36] Z. W. Geem, Harmony search algorithms for structural design optimization, vol. 239. Springer, 2009.

[37] X. Wang, X.-Z. Gao, and K. Zenger, An introduction to harmony search optimization method. Springer, 2015.

[38] J. Del Ser, Harmony Search Algorithm: Proceedings of the 3rd International Conference on Harmony Search Algorithm (ICHSA 2017), vol. 514. Springer, 2017. 
[39] L. Li, S. Chi, and G. Lin, "Chaos harmony search method and its application to local factor of safety method for soil slopes.," Yanshilixue Yu Gongcheng Xuebao/Chinese J. Rock Mech. Eng., vol. 25, pp. 2763-2769, 2006.

[40] M. Mahdavi, M. Fesanghary, and E. Damangir, "An improved harmony search algorithm for solving optimization problems," Appl. Math. Comput., vol. 188, no. 2, pp. 1567-1579, 2007.

[41] P. Chakraborty, G. G. Roy, S. Das, D. Jain, and A. Abraham, "An improved harmony search algorithm with differential mutation operator," Fundam. Informaticae, vol. 95, no. 4, pp. 401-426, 2009.

[42] Q.-K. Pan, P. N. Suganthan, M. F. Tasgetiren, and J. J. Liang, "A self-adaptive global best harmony search algorithm for continuous optimization problems," Appl. Math. Comput., vol. 216, no. 3, pp. 830-848, 2010.

[43] P. Zhang, P. Sun, and G. J. Li, "Opposition-based Learning Harmony Search Algorithm Solving Unconstrained Optimization Problems," in Advanced Materials Research, 2014, vol. 1006, pp. 1035-1038.

[44] J. Kalivarapu, S. Jain, and S. Bag, "An improved harmony search algorithm with dynamically varying bandwidth," Eng. Optim., vol. 48, no. 7, pp. 1091-1108, 2016.

[45] B. Naik, J. Nayak, and H. S. Behera, "A global-best harmony search based gradient descent learning FLANN (GbHS-GDL-FLANN) for data classification," Egypt. Informatics $J$, vol. 17, no. 1, pp. 57-87, 2016.

[46] H. Ouyang, L. Gao, S. Li, X. Kong, Q. Wang, and D. Zou, "Improved harmony search algorithm: LHS," Appl. Soft Comput., vol. 53, pp. 133-167, 2017.

[47] C. Peraza, F. Valdez, and O. Castillo, "Fuzzy harmony search algorithm using an interval type-2 fuzzy logic applied to benchmark mathematical functions," in Intuitionistic fuzziness and other intelligent theories and their applications, Springer, 2019, pp. 13-28.

[48] T. Zhang and Z. W. Geem, "Review of harmony search with respect to algorithm structure," Swarm Evol. Comput., vol. 48, pp. 31-43, 2019.

[49] A. Ala a, A. A. Alsewari, H. S. Alamri, and K. Z. Zamli, "Comprehensive review of the development of the harmony search algorithm and its applications," IEEE Access, vol. 7, pp. 14233-14245, 2019.

[50] J. Yi, C. Lu, and G. Li, "A literature review on latest developments of Harmony Search and its applications to intelligent manufacturing," Math. Biosci. Eng., vol. 16, no. 4, pp. 2086-2117, 2019.

[51] M. Nazari-Heris, B. Mohammadi-Ivatloo, S. Asadi, J.-H. Kim, and Z. W. Geem, "Harmony search algorithm for energy system applications: an updated review and analysis," J. Exp. Theor. Artif. Intell., vol. 31, no. 5, pp. 723-749, 2019.

[52] M. Kiani-Moghaddam, M. Shivaie, and P. D. Weinsier, Modern Music-Inspired Optimization Algorithms for Electric Power Systems. Springer, 2019.

[53] A. Askarzadeh, "Solving electrical power system problems by harmony search: a review," Artif. Intell. Rev., vol. 47, no. 2, pp. 217-251, 2017.

[54] D. Rahmani Dashti, A. Ghabeli, and S. M. Hosseini, "Solving static economic load dispatch using improved exponential harmony search optimisation," Aust. J. Electr. Electron. Eng., vol. 13, no. 2, pp. 142-150, 2016.

[55] M. A. Al-Betar, M. A. Awadallah, A. T. Khader, A. L. Bolaji, and A. Almomani, "Economic load dispatch problems with valve-point loading using natural updated harmony search," Neural Comput. Appl., vol. 29, no. 10, pp. 767-781, 2018.

[56] R. Kazemzadeh and A. Hatefi, "Intelligent tuned harmony search for solving economic dispatch problem with valve-point effects and prohibited operating zones," J. Oper. Autom. Power Eng., vol. 1, no. 2, pp. 84-95, 2007.

[57] B. K. Panigrahi, V. R. Pandi, S. Das, Z. Cui, and R. Sharma, "Economic load dispatch using population-variance harmony search algorithm," Trans. Inst. Meas. Control, vol. 34, no. 6, pp. 746-754, 2012.

[58] T. S. W. Journal, "Retracted: Dynamic Harmony Search with Polynomial Mutation 
Algorithm for Valve-Point Economic Load Dispatch,” Sci. World J., vol. 2016, 2016.

[59] Y. N. Zhang, "Harmony Search Algorithm with Opposition-based Learning for Power System Economic Load Dispatch," in Advanced Materials Research, 2015, vol. 1065, pp. 3434-3437.

[60] Z. W. Geem, "Economic dispatch using parameter-setting-free harmony search," J. Appl. Math., vol. 2013, 2013.

[61] Q. Niu, H. Zhang, X. Wang, K. Li, and G. W. Irwin, "A hybrid harmony search with arithmetic crossover operation for economic dispatch," Int. J. Electr. power energy Syst., vol. 62, pp. 237-257, 2014.

[62] H. Rezaie, M. H. Kazemi-Rahbar, B. Vahidi, and H. Rastegar, "Solution of combined economic and emission dispatch problem using a novel chaotic improved harmony search algorithm," J. Comput. Des. Eng., vol. 6, no. 3, pp. 447-467, 2019.

[63] Y. Jiao, J. Wu, Q. Tan, Z. Tan, and G. Wang, "An optimization model and modified harmony search algorithm for microgrid planning with ESS," Discret. Dyn. Nat. Soc., vol. 2017, 2017.

[64] B. Houari, L. Mohammed, B. Hamid, A. A. N. El Islam, M. Sara, and S. Abdallah, "Improved Dynamic Harmony Search Optimization for Economic Dispatch Problems with Higher Order Cost Functions," Univers. J. Electr. Electron. Eng., vol. 6, no. 5, pp. 303-313, 2019.

[65] G. Mokhtari, A. J. Ghanizadeh, and E. Ebrahimi, "Application of imperialist competitive algorithm to solve constrained economic dispatch," Int. J. Electr. Eng. Informatics, vol. 4, no. 4 , p. 553, 2012.
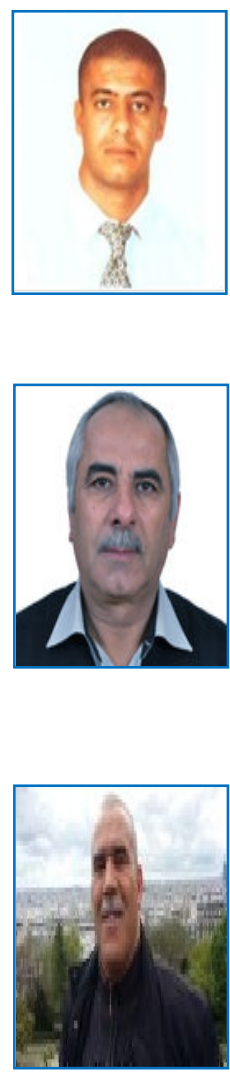

Houari Boudjella was born in Ain Temouchent, West of Algeria in 1981. He is a Ph.D student at USTO-MB, Oran, Algeria. His research interests based on power system management, FACTS, optimization theory, power system generation, control, and Smart Grid.

Mohamed Laouer is an Assistant Professor in at SALHI Ahmed university center, Naama, (Algeria). He received his $\mathrm{PhD}$ degree from USTO-MB (Algeria). His research interests include power systems optimization, FACTS and Smart Grid

Hamid Bouzeboudja is an Assistant Professor at the Department of Electrical Engineering, USTO-MB (Oran, Algeria). He received his $\mathrm{PhD}$ degree from USTO$\mathrm{MB}$ in 2004. His research interests include power system generation and control, smart grid and evolutionary methods. 


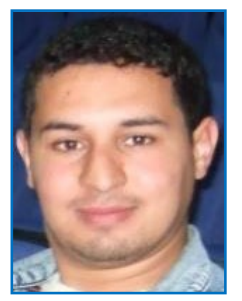

Ayad Ahmed Nour El Islam was born in Algeria 1985. He received his master degree in electromagnetic compatibility from Djilali Liabes University, Algeria in 2011. Currently, Ph.D in Electrotechnics in Djilali Liabes University. His major fields of interest are eddy current and magnetic separator process.

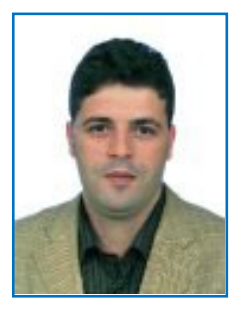

Benhamida Farid is an Assistant Professor in the Department of Electrical Engineering, UDL-SBA, Algeria. His research interests include electrical engineering, artificial intelligence algorithms, computing in mathematics, wind power and power systems.

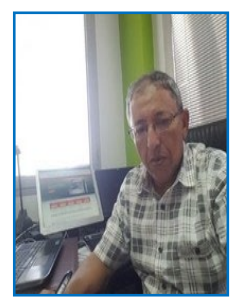

Abdallah Saad is an Assistant Professor in the Department of Electrical system Engineering, ENSEM, University Hassan II, Casablanca, Morocco. Founder, scientific and technical advisor of Normindus, a cabinet of studies and engineering in electricity and automation. He received his PhD degree from Grenoble INP in 1986 (France). His research interests include renewable energy systems in smart cities, engineering offices, equipment development companies. 